University of Rhode Island

DigitalCommons@URI

Open Access Master's Theses

1975

\title{
The Effect of Couple Participation in Childbirth Preparation on Postpartum Parenthood Adjustment
}

Joyce M. Anderson

University of Rhode Island

Follow this and additional works at: https://digitalcommons.uri.edu/theses

\section{Recommended Citation}

Anderson, Joyce M., "The Effect of Couple Participation in Childbirth Preparation on Postpartum Parenthood Adjustment" (1975). Open Access Master's Theses. Paper 1166.

https://digitalcommons.uri.edu/theses/1166

This Thesis is brought to you for free and open access by DigitalCommons@URI. It has been accepted for inclusion in Open Access Master's Theses by an authorized administrator of DigitalCommons@URI. For more information, please contact digitalcommons-group@uri.edu. 


\section{THE EFFECT OF COUPLE PARTICIPATION IN CHILDBIRTH PREPARATION ON POSTPARTUM PARENTHOOD ADJUSTMENT}

BY

JOYCE M. ANDERSON

A THESIS SUBMITTED IN PARTIAI FULFILLMENT OF THE REQUIREMENTS FOR THE DEGREE OF MASTER OF SCIENCE IN CHILD DEVELOPMENT AND FAMILY RELATIONS 


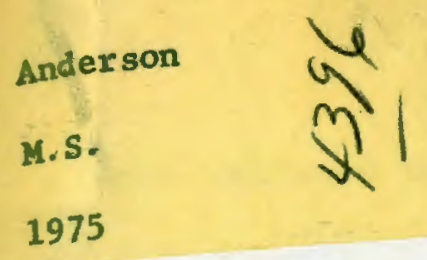

Anderson

M.S.

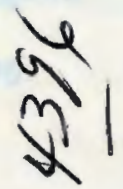

SCIENCE THESIS

OF

1975

M. ANDERSON

COLOR NO.: $\quad 2460$

Binding $3 / 8 / 76$

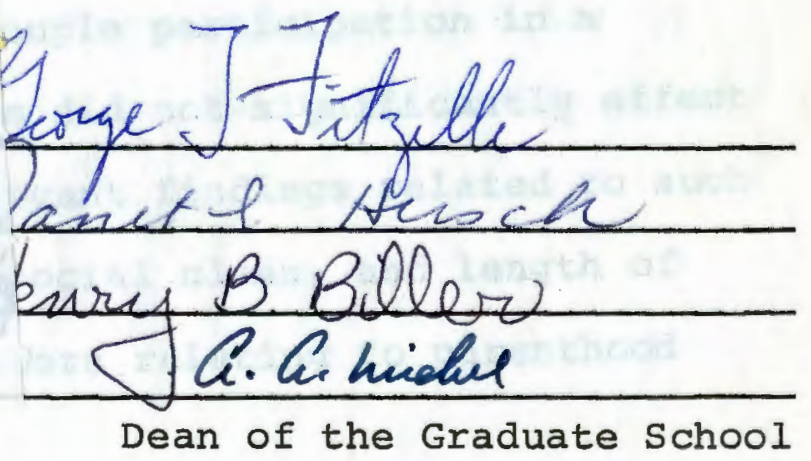

UNIVERSITY OF RHODE ISLAND 


\section{Abstract}

The purpose of this study was to examine the effect of couple participation in childbirth preparation classes on parenthood adjustment during the initial six-week postpartum period. Subjects were recruited through the Childbirth Education Association of Rhode Island and local obstetricians. Of the original 42 primiparous couples contacted during the last trimester of their pregnancies, 25 completed the requirements of participation by filling out two questionnaires, which included the Locke and Wallace Short Marital Adjustment Scale (1959), the Beauchamp Parenthood Adjustment Scale (1968), and additional demographic data. Although couple participation in a childbirth preparation program did not significantly affect parenthood adjustment, significant findings related to such variables as age, education, isocial class, and length of marriage were found to be factors relating to parenthood adjustment. 


\section{Acknowledgements}

Writing this thesis would have been an impossible task without the help of many kind and supportive people. I would like to express my sincere gratitude to all of them: to my advisor, Dr. George T. Fitzelle for his patience and sympathetic understanding; to my committee members, Janet Hirsch for her enthusiastic support and Dr. Henry Biller for his advice and suggestions; to Dr. John Ferris who helped locate subjects and to the Childbirth Education Association of Rhode Island who suggested members of their group as subjects; to Susan M. Horvath of the University of Rhode Island Computer $\mathrm{Lab}$ who helped unravel the statistics; to Dody Giletti for editing and typing; and to my family for their ongoing support and love. 
Table of Contents

I. Introduction 1

Statement of the Problem 2

II. Review of the Literature 4

Selected Studies 4

Parenthood Preparation 8

III. Method 15

Sample Selection $\quad 15$

$\begin{array}{ll}\text { Procedure } & 17\end{array}$

Measurement 18

$\begin{array}{ll}\text { Statistical Analysis } & 19\end{array}$

IV. Results 21

Correlations: Hypothesis Number One 21

Correlations: Hypothesis Number Two 32

Data Analysis: Hypothesis Number Three 34

Mean Profiles 39

"Bothersome" Items on the Beauchamp Scale 42

Physical and Emotional Difficulties 44

$\begin{array}{ll}\text { V. Discussion } & 47\end{array}$

Significant Differences $\quad 58$

Significant Findings $\quad 59$

"Bothersome" Items 61

Suggestions for Future Research 62

VI. Summary 64

Bibliography $\quad 66$

$\begin{array}{ll}\text { Appendix } & 70\end{array}$ 
List of Tables

I. Husbands and Wives in Experimental

and Control Groups: Means and

T-Ratios of Age, Education Completed,

and Marital and Parenthood Adjustment Scores

II. Experimental and Control Groups:

Means and T-Ratios of Length of Marriage

and Social Status Score, and Social Class

III. Best Parenthood Adjustment:

Two Couples From Experimental and

From Control Groups Compared on All Variables

IV. Poorest Parenthood Adjustment:

Two Couples From Experimental and

From Control Groups Compared on All Variables

v. Comparison of Husbands and Wives in

Experimental and Control Groups:

Means of Age, Education Completed,

Annual Income, Social Class, and

Marital and Parenthood Adjustment Scores

VI. Husbands and Wives in Entire Sample:

Means, Standard Deviations, and Ranges of Age, Education Completed, Length of Marriage, Social status Score, and Marital and Parenthood Adjustment scores

VII. Husbands and Wives in Experimental Group: Means, Standard Deviations, and Ranges of Age, Education Completed, Length of Marriage, Social status Score, 
vii

and Marital and Parenthood Adjustment Scores

VIII. Husbands and Wives in Control Group:

Means, Standard Deviations, and Ranges

of Age, Education Completed, Length of

Marriage, Social Status Score,

and Marital and Parenthood Adjustment scores 
CHAPTER I

INTRODUCTION

The birth of the first child, bringing about transition from the marital dyad to the familial triad involves much adjustment on the part of both husband and wife. The postpartum period will be a time of less stress and more enjoyable participation on the part of both parents if the husband and wife actively participate in preparation for and in the birth of their first child, as well as parenthood adjustment will be greater for such couples than for those couples who have not participated in preparation. I have been interested in determining whether an aspect of this togetherness factor of husband-and-wife participation, as well as childbirth preparation for both husband and wife, produces better parenthood adjustment during the postpartum period.

Robert Winch (1968) lists replacement as one of five basic societal functions, stating that such replacement can occur through birth or recruitment of persons from other societies and that "The core relationship for the function of replacement is husband-wife-offspring."

There have been studies indicating that preparation for childbirth by both husband and wife has a positive influence on adjustment to the birth of the first child (Liebenberg, 1967; Bibring et al., 1961; Gordon et al.' 
1965; Parke and O'Leary, 1974). Other studies have indicated the need for some kind of preparation for parenthood (LeMasters, 1957; Hobbs, 1965; Dyer, 1963; Rossi, 1968).

Conceptualization about parenthood preparation has been looked at from many points of view, such as crisis theory, adjustment to the addition of a third member to an established dyad, role change, and life-stage theory. Because there exist so many ways of examining parenthood preparation and adjustment, in-depth studies are needed. This study is one which investigates the question of whether couples preparing together for the labor and delivery of their first child share roles more, have less marital tension, and enjoy their new baby more.

\section{Statement of the Problem}

There is no doubt that the transition to parenthood is a difficult one and that the couple's adjustment to the familial triad is affected by many variables. Therefore, this study was structured to investigate three hypotheses concerning parenthood preparation:

Hypothesis Number One--that such variables as age, education, social status, length of marriage, prenatal marital adjustment, and postpartum marital adjustment affect adjustment to parenthood; 
Hypothesis Number Two--that prenatal marital adjustment correlates significantly with postpartum marital adjustment; and

Hypothesis Number Three--that couples' participating together in preparing for the birth of their first child will significantly affect their adjustment to parenthood. 
CHAPTER II

REVIEW OF THE LITERATURE

\section{Selected studies}

The transition to parenthood, considered by Erikson (1963) to be one of eight developmental stages of life, is seen by some as a crisis, by others as a difficult adjustment, and by still others as a crucial event. In many cases, it is an event which necessitates role change for the family members; it is a significant focal point in the life of the marriage. Using Hill's (1949) definition of crisis-"any sharp or decisive change for which old patterns are inadequate"--the birth of the first child to a couple inexperienced in the care of their own infant, with 24-hour sole responsibility, might easily be called a crisis event. The two-person group is considered to be the most stable human relationship, whereas the three-person group falls into the pattern of a pair and an isolate, a most volatile human relationship (Wilson and Ryland, 1949). The structure of the three-person group is infinitely more complex than that of the two-person group, where relationships are relatively straightforward, the husband and wife interacting directly. Introduce a baby into the family group and there is not only interaction between father and mother, and each parent and baby, but the mother-child 
relationship is affecting and is affected by the father and the father-child relationship affects and is affected by the mother (Biller and Meredith, 1975). Consider the following diagram from Biller and Meredith's recent book, Father Power (1975).

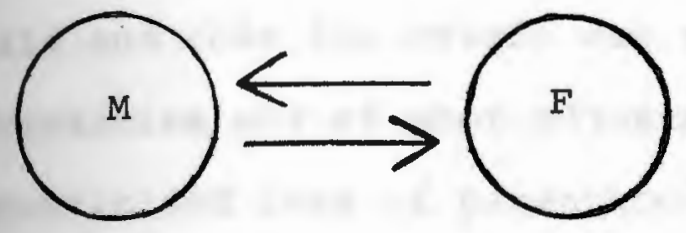

Before Baby

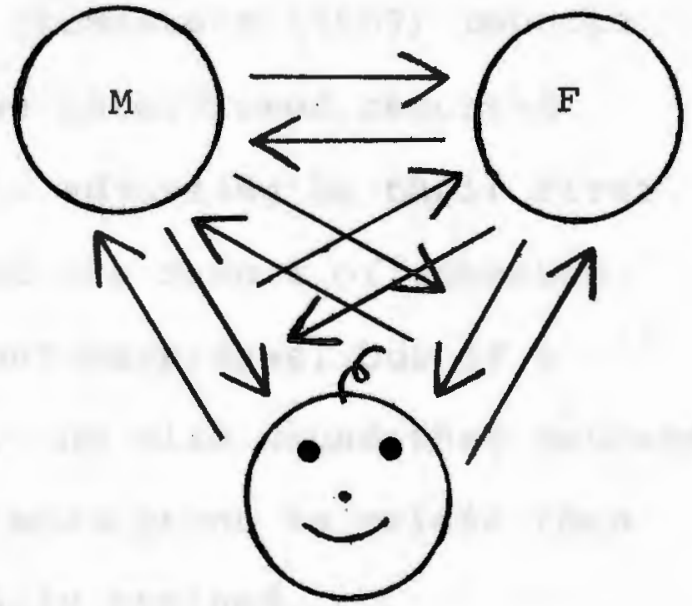

After Baby

Not only does the arrival of the first child call for major behavioral changes on the part of the new parents, but these behavioral changes have an impact on the existent relationship between them. Sociologists (Lake, 1974) give three reasons why the transition to parenthood may be a traumatic experience for the couple:

1. The abrupt arrival of the baby;

2. The lack of preparation for this major role in life;

3. No revocation of such: the baby cannot go back where it came from. 
Crisis, transition, critical period, whatever, it is a time of change and a period of adjustment. Perhaps Alice Rossi's (1968) term, "normal crisis of parenthood,". is the most applicable here.

Research in the field of parenthood adjustment reveals non-conclusive results. LeMasters (1957) reports $83 \%$ of those middle class couples interviewed reported "extensive" or "severe" crisis in adjusting to their first child and that the crisis was not the result of unwanted pregnancies nor of poor adjustment marriages, but of a romanticized idea of parenthood. He also found that mothers with professional training were more prone to crisis than mothers who were non-professionally trained.

Not knowing what to expect with a new baby was the theme of David Mace (1958) in a magazine article. Mace claimed that new parents were unaware that they would have angry, resentful feelings toward each. other and the baby, and that these feelings are the natural outcome of the new triad. This least adult of all human beings, the newborn, difficult to understand and decode, can cause acute anxiety and confusion in new parents who have had little or no experience with babies (Blood, 1972). Both Mace (1958) and LeMasters (1957) advocated in the late fifties better preparation for couples anticipating parenthood. Preparation for parenthood is cited again and again by researchers in their studies of this transition from marital dyad to familial triad. E.D. 
Dyer found that couples having had some type of marriage courses in high school or college were better prepared and aperienced less crisis with the birth of their first child, but were still offering "be prepared" advice to other parents-to-be. In fact, Dyer (1963) found that the degree of crisis experienced with the birth of the first child was related to four factors:

(1) parents' preparation for marriage and parenthood; (2) the state of the marriage and family organization when the child was born; (3) parents' marital adjustment after the child's birth; and (4) their social and situational background, including use of contraception, child's age, and length of marriage. Dyer (1963) found less crisis significantly related to those parents (1) having taken marriage courses in high school or college, (2) rating marriage as excellent after the birth of the first child, (3) who planned parenthood and followed plan, (4) whose child was six months or older, (5) with men having a college degree; (6) married three years or more. Dyer's (1963) research reiterated LeMasters' (1957) contention that emphasis on preparation for parenthood can probably make an important contribution to young marrieds who are contemplating parenthood.

Hobbs (1965) reports beginning parenthood to be hardly a crisis at all but a somewhat stressful period which necessitates, within the family, rearrangement in role and status interrelations. His significant findings were that 
fathers and mothers differed on the crisis variable and that scores of the sexes were not correlated. Dyer's (1963) findings indicated that mothers' and fathers' "crisis manifestations" were similar but were listed in different orders of acuteness.

Feldman and Rogoff (undated) cite Feldman's earlier research which reported parents who had infants only were more resentful and had more arguments than parents in any other life stage. Feldman's (undated) later study focused on what variables are associated with changes in marital satisfaction after the arrival of the first child and found that two seemingly opposing variables--that of the companionate marriage and that of the differentiated marriage--were positively correlated with increased marital satisfaction after the birth of the first child. Benson (1968) reports that all favorable adjustments to marriage before children are born serve to increase the couple's ability to cope with later family stresses and, conversely, that delays in marital adjustment or accommodation will increase the probability of difficulties. The author cites, however, the great dearth of concerted research into the relationship between marital adjustment and parental performance.

\section{Parenthood Preparation}

It would seem that there are cultural influences, too, which contribute to the difficulty of becoming parents. 
Brenton (1966) feels that men are unprepared for the new demands of fatherhood and, lacking readiness, many fathers face the prospect of parenthood with real foreboding and genuine feelings of inadequacy. There is little concept in this society of preparing for the fathering role, and neither fatherhood nor "husbandhood" is seen by men as their chief role in life: "Only very occasionally, for boys, is fatherhood added like an afterthought as part of their self-image as mature men" (Bruno Bettelheim, as cited in Benson, 1968).

Perhaps it is a lack of preparedness and involvement on the part of the fathers in early weeks of fatherhood that leads to the findings of Meyerowitz and Feldman (1966) that "wives agreed more than husbands did, that it is harder to be a parent than I imagined." Perhaps there is no amount of preparedness for the actual task of parenting. Women, who view motherhood as their chief role in life, will direct their attention and energy to the infant, whose needs are at a maximum during the postpartum period, leaving the father feeling neglected and inadequate, shoved out of the favored position he once held with his wife (Lopata, 1965).

Recent studies on pregnancy and childbirth for first-time fathers show that it is a stress time for them as well as their wives (Arnstein, 1972). (In primitive cocieties, the practice of couvade takes place where the husband goes through simulated labor and delivery, asserting 
his rightful paternity and proclaiming his share of Mrenthood.) Arnstein (1972) recommends focusing on the Importance of free and open communication between husband and wife, talking things out, sharing their worries and doubts. Sharing the pregnancy and approaching parenthood as much as possible is the recommendation of many researchers and writers in the field of parenthood. Liebenberg (1967) found that husband participation in prenatal and postpartum counseling had almost uniformly facilitated communication and closeness between husband and wife, and that increased understanding of a husband's involvement with his wife's pregnancy and childbirth points toward preventive intervention with fathers who have shown personality disturbances, exaggerated dependence, and acting out in connection with their recent fatherhood.

Lynn (1964) reports that expectant fathers have been found to experience psychosomatic illness in the abdominal region, restlessness, anxiety, and sleeplessness, and that their acting-out behavior often takes the form of drinking heavily, becoming involved with other women, working frantically, worrying irrationally about their wives' health, and sharply decreasing their sexual activity with their wives. The pregnancy and birth of his first child may intensify the husband's feelings of separation, reactivate conflicts with his own parents, and heighten dependency needs (Lynn, 1974). Hartman and Nicolay (1966) found that, 
in a group of men with police records, the number of sex offenses in the wife-pregnant group was far greater than those with non-pregnant wives. Bibring et al. (1965) suggest, in their study of the psychological process in pregnancy and earliest mother-child relations, that the husband should be involved in the pregnancy, that he should have a useful activity while his wife is in labor, and that a woman giving birth should not be alone in a labor room-for a lonely laboring woman is one with more unrealistic complaints and demands during her labor and delivery. A woman having a baby needs a great deal of individualized attention (Bibring et al., 1965).

Larsen (1966), in a study on the stresses of childbearing, reports the dominant stress during labor and delivery was the wife's unmet need of adequate help and comfort from nurses, doctors, and husbands. After delivery, as attention to the mother decreases, her responsibilities increase, resulting in emotional upsets, nervousness, fatigue, and depression. Support for individual mothers in labor would appear to be very important, since help or lack of help a mother receives in labor seems to be long remembered with feeling.

The impact of childbearing on the mother is often minimized, whereas the impact on the father is often unrecognized. Miller (1971) reports cases of subjects in their seventies who remember clearly how important it was in 
their lives to have been present at the birth of their first child: "It appears that women never forget their childbirth experiences . . ask any woman to tell you about her labor and delivery and she will tell you the hour and minute of the most seemingly insignificant details." Miller (1971) feels that the father, too, has great need for support, reassurance, explanation of how things are and what to expect: "a father has the right to experience the joy of birth."

Tanzer (1968) reports a comparative study of 22 women whose husbands were with them during labor and delivery and 14 women who were alone. Only women whose husbands were at their side during labor or delivery reported rapture or near-mystical bliss during childbirth. At one month postpartum, the husband-present group showed a far more narrowing gap between self and ideal self than did the control group. The husband-present group described joy, excitement, feelings of continuity, and positive first contact with their babies. Several of the husbands in the one-month postpartum interview, eager to be interviewed themselves, showed an intense interest in the whole process of childbearing. The control group described negative emotions, a gap in continuity, and feelings of superiority and condescension toward their husbands (Tanzer, 1968). Huttel et al. (1972), in their study conducted in Germany of couples prepared in the psychoprophylaxsis method of 
childbirth, report the experimental group's wish for more children was enhanced significantly and that they had more actively mastered the delivery. The fathers were found to be not only a major asset to their wives but also an effective help to an overworked nursing staff, "producing an atmosphere of calmness and dignity in the delivery room" (Huttel et al. , 1972).

Wenner (1969) describes the pregnancy period as one of great emotional and physiological change, where motivation for success is particularly high and where the husband is involved in numerous ways, as well as the whole marital relationship. Gordon et al. (1965) found that prenatal instruction was shown to help expectant mothers manage their new responsibilities successfully, and thus reduce postpartum emotional distress. Mothers whose husbands had received special prenatal instruction with their wives developed less than half the emotional problems than did mothers who participated alone. Parke and O'Leary (1974) found that fathers who had been present at the delivery of their babies were active participants in the familial triad during their wives' hospital stay.

Biller and Meredith (1975) recommend that the husband and wife choose and consult the obstetrician together and take part in exercise programs or childbirth training classes as well: "Supporting your wife will help, not only her, but also the actual physical well-being of the 
unborn child." They feel that the presence of a well prepared husband at his wife's side during labor and delivery can be a great help to the wife, a calming influence, and a profoundly moving experience, which will influence his Eatherhood and his subsequent relationship with his wife. They claim that there is an important imprinting that takes place when the father is present at the birth of his child and an involved father with his newborn child is affected by this participation in labor and delivery. 


\section{CHAPTER III}

METHOD

\section{Sample Selection}

The experimental group consisted of 14 couples who were due to deliver their first babies in February and March of 1975, and who were participating in classes given by the Childbirth Education Association of Rhode Island. The CEA of Rhode Island is involved in a prenatal program which prepares couples for family centered maternity care. Classes, based on the Lamaze method of childbirth, consist of an orientation class in which there is a tour of the hospital followed by a film about childbirth and a discussion of prepared childbirth, and six subsequent weekly seminars led by a trained teacher, and given during the eighth month of the pregnancy. Seminars concentrate on practical instruction in relaxation and breathing techniques used in labor and delivery in which husbands, knowledgeable about these techniques, offer support to their wives. There is also discussion of childbirth-related topics as well as the physiology of pregnancy. During the classes, the couples are able to question and discuss pregnancy, labor and delivery, childbirth, and the emotions that are commonly experienced at this time. The supportive role of the father is emphasized throughout the process so that the birth of 
the baby will become a meaningful and enriching family experience. In addition, a postpartum class is given after delivery for mothers, fathers, and babies.

Names of the couples were submitted to the researcher by the registrar of $\mathrm{CEA}$, and the couples were then contacted by telephone and asked whether they would be willing to participate in the study by completing two questionnaires, one administered within one month before the due date and the other administered six weeks after the baby was born. Twenty couples were contacted, three (15\%) of whom refused and three (15\%) of whom did not complete one or the other of the questionnaires.

The control group consisted of 11 couples who were participating in traditional labor and delivery, and who did not participate in preparation classes. These couples were contacted through local obstetricians who submitted names of couples expecting their first baby in February or March of 1975. Of the 22 names submitted, eight (36\%) couples could not be contacted due to lack of telephones, two (98) couples refused, and one (5\%) failed to return the second questionnaire. It was particularly difficult to match the control sample to the experimental sample, due to the reluctance of many local obstetricians to become involved in such a study and to submit patients' names. It was, therefore, necessary to use all the names given to the researcher, without being able to cull out those couples who 
did not match the experimental group. It should be noted here that the birth rate for the state of Rhode Island was down for the month of February 1975. Birth rates, based on occurrences of births in the state, were 930 births, or 12.9 per 1000 in February 1974 and 795 births, or 10.9 per 1000, in February 1975. March rates were 962 births, or 12.4 per 1000, for 1974 and 905 births, or 11.2 per 1000 , for 1975 .

\section{Procedure}

All couples were contacted by telephone and asked whether or not they would be willing to participate in a research study being done on the birth of the first child. Questions pertaining to the investigator's qualifications were answered but questions pertinent to the research were not answered with the explanation that the answers might influence future responses from the subjects. The couples were asked to complete the questionnaires upon receiving them and to return them to the investigator immediately. They were also requested to inform the investigator of the birth of the baby as soon as it was convenient for them to do so, either by mail or telephone. It was, in many cases, necessary for the investigator to call the couples to find out when the babies had been born. Six weeks after the baby was born, each couple received a second set of questionnaires with instructions to complete them on the six-week post- 
partum day and return them to the investigator.

Measurement

Meyerowitz (1970) and Kirkpatrick (1971) have both found a positive correlation between marital adjustment and parenthood adjustment; therefore, the Locke and Wallace Short Marital Adjustment Scale (1959) was used as well as Beauchamp's Parenthood Adjustment Scale (1968) to determine whether the two groups differed significantly in marital adjustment and parenthood adjustment.

The first questionnaire consisted primarily of the Locke and Wallace Scale, a 15-item Likert-type scale constructed to be a short form of the Burgess Locke Index of Marital Adjustment. Locke and Wallace (1959) report the split half reliability to be .90 , having measured validity by correlating prediction scores with adjustment scores of 236 husbands and wives. This test has been validated as predictive of marriage stability with a mean of 135.9 for a well-adjusted group and 71.7 for a maladjusted group. In addition to the Locke and Wallace scale, there were a number of questions pertaining to age, length of marriage, education, income and occupation of the husband, plans for additional children, experience with infants, physical complications during the pregnancy, and possible emotional or physical illness of either husband or wife. The second questionnaire consisted of Beauchamp's 
36-item Iikert-type Adjustment to Parenthood Scale, which measures management type adjustments necessitated by the infant's presence in the family. Possible scores range from 36 to 144, with a high score indicating much difficulty in adjusting to the infant's presence and a low score indicating nearly no difficulty. The second questionnaire also contained questions pertaining to physical

complications during labor and delivery, physical or emotional difficulties since the birth of the baby, and previous courses or classes, other than those given by CEA of Rhode Island, which might have been helpful in preparing for parenthood.

In order to determine social status, Hollingshead's Two Factor Index of Social Position (1957) was used. The education and occupation of the husband were scored and weighted, then added together, the resulting score indicating the social class of each couple, with class I the highest social class and Class $\mathrm{V}$ the lowest.

\section{Statistical Analysis}

The analyses concentrated on comparing the experimental group scores with the control group scores on the Locke and Wallace Short Marital Adjustment Scale, given twice, and on the Beauchamp Parenthood Adjustment Scale, given at six weeks postpartum. The t-ratio was used because it is considered to be a strong, accurate test constructed 
for use with small groups. The t-ratio was also used to determine whether there were significant differences between the two groups in variables such as age, education, social status, and length of marriage, since the groups were randomly chosen and not matched.

To determine whether there might be a correlation between each of the variables--age, education, social status, length of marriage, marital adjustment, and the variable of parenthood adjustment--Pearson Product-Moment Coefficients of Correlation were used. Values on the Pearson Product-Moment Coefficient of Correlation might be used as a way to predict parenthood adjustment. 
CHAPTER IV

RESULTS

Correlations: Hypothesis Number One Results pertaining to Hypothesis Number One--that such variables as age, education, social status, length of marriage, prenatal marital adjustment, and postpartum marital adjustment affect adjustment to parenthood--are reported in this section (see Table I).

Significant difference, as measured by the t-ratio, was found at the .0I level between the groups of husbands for the variable of age. Mean age for experimental husbands was 27.6 years and for the control husbands was 23.3 years. Significant difference between the .0I level and the .05 level was found between the two groups of wives for the variable of education. Mean education level for the experimental wives was 15.1 years of completed education and mean education level for the control wives was 13.0 years of completed education.

Significant differences at the level of .05 were found between the two groups of wives for the age variable and between the two groups of couples for the variable of social status. Mean age for experimental wives was 25.7 years and for the control wives was 22.4 years of age. Social status mean for the experimental group was 38.6 , 
Table I

Husbands and Wives in Experimental and Control Groups: Means and T-Ratios of Age, Education Completed, and Marital and Parenthood Adjustment scores

Variables

Age (years)

Husbands

Wives

Education Completed (years)

Husbands

Wives

Marital Adjustment Scores

Prenatal

Husbands

Wives

Postpartum

Husbands

Wives
Means for Groups

Exptl. Control

$(\mathrm{N}=14)(\mathrm{N}=11)$
T-Ratios

$\begin{array}{lll}27.6 & 23.8 & 2.8236^{* * * *} \\ 25.7 & 22.4 & 2.0921^{* *}\end{array}$

$\begin{array}{lll}15.0 & 13.1 & 1.7362^{*} \\ 15.1 & 13.0 & 2.3844^{\text {** }}\end{array}$

$\begin{array}{lll}110.4 & 108.9 & .2113 \\ 109.7 & 114.5 & .5990\end{array}$

$109.9 \quad 115.9$

.4553

$113.5 \quad 118.4$

.5604

Parenthood Adjustment score

Husbands

Wives
50.6

58.2
49.5

54.5
.1463

.7756

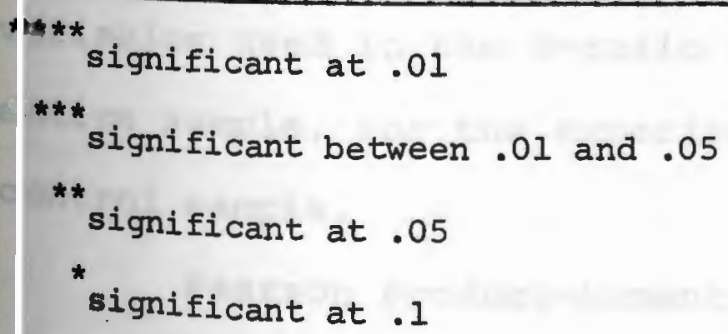


which was well within the range for level II, and for the control group was 54.3, which was well within the range for level III (see Table II).

Less significant, but statistically significant at the .1 level, was the difference between the two groups of husbands for the variable of education. Mean education level for the experimental husbands was 14.9 years of completed education and for the control husbands was 13.1 years of completed education. Approaching significance at the .1 level was the difference between the two groups' length of marriage. Mean length of marriage for the experimental group was 3.3 years and for the control group was 2.2 years.

There were no significant differences found between the two groups for the variables of marital adjustment or parenthood adjustment. Tables I and II show t-ratios and means for both groups for variables of age, education, prenatal marital adjustment, postpartum marital adjustment, parenthood adjustment, social status, and length of marriage. Tables VI, VII, and VIII, which can be found in the appendix, show means, standard deviations, and ranges of variables used in the t-ratio analysis of variables for the entire sample, for the experimental sample, and for the control sample.

Pearson Product-Moment Coefficients of Correlation were done for the entire sample as well as for the 
Table II

Experimental and Control Groups:

Means and T-Ratios of Length of Marriage and Social Status Score, and Social Class

Variables

Length of Marriage (years)

Social status Score

Social Class

\section{Means for Groups}

Exptl. Control

$(N=14)(N=11)$
T-Ratios

$3.3 \quad 2.2 \quad 1.5060$

38.9

54.3

$2.0933^{* *}$

II

III

$\star$

Rignificant at .05 
experimental group and the control group in order to determine significant correlations considering Hypothesis Number One--that such variables as age, education, social status, length of marriage, prenatal marital adjustment, and postpartum marital adjustment affect adjustment to parenthood. (The entire computer program is available in the Department copy of this thesis.) While considering these correlations, it is important to note that low scores on the Beauchamp scale indicate good parenthood adjustment, which accounts for the negative correlations cited.

Entire Sample

Parenthood for the entire group of 25 couples was negatively correlated with postpartum marital satisfaction at the .05 level. Couples who received higher satisfaction scores on the Locke and Wallace Short Marital Adjustment Test given postpartum also had significantly fewer parenthood adjustment problems, as measured by Beauchamp's scale.

Parenthood adjustment scores for the entire husband sample were negatively correlated with husband marital adjustment scores, before the babies were born, at the .07 level and, after the babies were born, at the .03 level. Those husbands who received high adjustment scores on the Locke and Wallace scale experienced fewer adjustment problems as measured by the Beauchamp scale. Marital 
satisfaction after the babies were born correlated more significantly with parenthood adjustment than did marital adjustment before the babies were born, indicating the strong influence parenthood adjustment has on marital satisfaction. Significant negative correlation was also found between parenthood adjustment of the husbands and postpartum marital satisfaction of the wives at the level of .03. As the wives' marital satisfaction increased, the husbands' parenthood adjustment scores decreased, indicating better parenthood adjustment for husbands of wives with high marital satisfaction.

There were no significant correlations found between wives' parenthood adjustment scores and the variables of age, education, social status, length of marriage, prenatal marital adjustment, or postpartum marital adjustment when product-moment correlations were computed.

Postpartum marital adjustment. for husbands correlated negatively with their education at the .05 level of significance. For husbands, as their education level increased, their postpartum marital adjustment scores declined.

Significant at the .1 level was the negative correlation between wives' postpartum marital adjustment and the couples' parenthood adjustment. As the wives' postpartum marital satisfaction increased, their parenthood adjustment problems declined. 
Wives' education correlated negatively with wives' marital adjustment at the .01 level of significance and with the couples' marital adjustment at the .06 level of significance. As wives' and couples' marital satisfaction increased, their education level decreased.

Parenthood adjustment for husbands correlated negatively with the couples' postpartum marital adjustment at the .01 level. As postpartum marital adjustment increased, the husbands' parenthood adjustment scores declined, indicating good parenthood adjustment.

Prenatal marital adjustment for wives correlated negatively with husbands' age at the .07 level of significance and with wives' education at the .01 level of significance. As wives' marital adjustment increased, their education level decreased and husbands' age declined.

Postpartum marital adjustment for wives and husbands correlated negatively with the couples' parenthood adjustment at the .1 and .06 levels of significance respectively. As the wives' and husbands' postpartum marital adjustment increased, their combined parenthood adjustment scores declined, indicating good parenthood adjustment.

Another correlation, significant at the .I level, was that between the social status of the couple and the prenatal marital satisfaction of the wife. As the social status scores rose, indicating placement in a lower social 
class, wives' marital satisfaction rises, indicating greater marital satisfaction for wives in lower social levels. The only significant correlation for wives' parenthood adjustment was that with husbands' parenthood adjustment, at the .0002 level. As wives' parenthood adjustment increased, husbands' parenthood adjustment increased.

\section{Experimental Group}

Computing Pearson Product-Moment Coefficients of Correlation for the experimental group alone resulted in some significant correlations which were not found for the entire sample.

Parenthood adjustment scores for the experimental husbands were negatively correlated with the age of the husbands at the .03 level, the age of their wives at the .009 level, the education of the wives at the .07 level, the length of marriage at the .08 level as well as the marital satisfaction scores. There was also a significant correlation between husbands' parenthood adjustment scores and social status at the .009 level. As social status scores became higher, indicating placement in lower social class, parenthood adjustment scores increased, indicating poor parenthood adjustment. Parenthood adjustment for the husbands also correlated with their wives' parenthood adjustment at the .02 level of significance and negatively 
with their wives' postpartum marital adjustment at the .07 level of significance. As wives' postpartum marital adjustment and parenthood adjustment increased, husbands' parenthood adjustment increased. Husband parenthood adjustment also correlated negatively with the couples' postpartum marital adjustment at the .09 level of significance. Couples' postpartum marital adjustment Increased when husbands' parenthood adjustment scores decreased, indicating good parenthood adjustment for husbands.

Those husbands who were older than the mean, whose marriages were longer, whose wives' education level was higher, and who were in a higher social class received lower scores on the parenthood adjustment scale, indicating better adjustment. There were no significant correlations for the parenthood adjustment of the group of experimental wives.

Parenthood adjustment for the experimental couples showed a negative correlation, significant at the .l level, with the age of the wives, indicating that better parenthood adjustment was experienced for those couples with the wife older than the mean age for the group of wives. Couple parenthood adjustment correlated with the social status of the couple at the significance level of .02 , indicating that the higher the social status score of the couple--that is, the lower the social class--the poorer was their adjustment to parenthood. 
Length of marriage correlated both with the prenatal marital adjustment of the wives at the .08 level of significance and that of the couples at the .06 level of significance. As length of marriage increased, prenatal marital satisfaction increased for the wives and for the couples. Prenatal marital adjustment for the husbands correlated with the age of their wives at the .07 level of significance and with the prenatal marital adjustment of their wives at the .08 level of significance.

Husbands' parenthood adjustment was better than that of their wives and correlated with several variables, whereas wives' parenthood adjustment did not correlate significantly with any variables other than their husbands' parenthood adjustment.

Control Group

Prenatal marital adjustment for the control group couples correlated negatively with the age of the husbands at the .06 level of significance, with the education of the wives at the .04 level of significance, and with the length of marriage at the .05 level of significance. As the couple's prenatal marital adjustment increased, husband's age decreased, wife's education decreased, and length of marriage decreased. Prenatal marital adjustment for wives was also negatively correlated with age of husbands at .05 , with education of wives at .06 , and with length of marriage 
at .02 .

Postpartum marital satisfaction for wives correlated negatively with age of husbands at .06 , with education of husbands at .01, with education of wives at .09, and positively with social status at .003 . As wives' prenatal and postpartum marital satisfaction scores increased, their husbands' age decreased, their education decreased, length of marriage decreased, and social status scores increased, indicating placement in lower social class.

Postpartum marital satisfaction for husbands correlated negatively with age of husbands at .04 , with age of wives at .08 , with education of husbands at .009 , and positively with social status at .02 . As husbands' postpartum marital satisfaction increased, their age and education decreased, and the age of their wives decreased. Couples' postpartum marital satisfaction scores also correlated negatively with age of wives at .08 , with education of husbands at .005 , and positively with social status at .006 levels of significance. As age of wives increased and, more significantly, as education of husbands increased, marital satisfaction declined. Also, as social class became lower, marital satisfaction became greater. It is noted here that couples within the control group with some characteristics similar to those in the experimental group--such as older wives, more highly educated husbands, and higher social class--were experiencing less marital 
satisfaction and more troubles adjusting to parenthood.

Husband parenthood adjustment correlated negatively with husband postpartum marital satisfaction at the .04 level of significance. As husbands' postpartum marital adjustment scores increased, their parenthood adjustment scores decreased, indicating good parenthood adjustment. Parenthood adjustment scores for husbands correlated highly with their wives' parenthood adjustment scores at the .0009 level of significance.

Correlations: Hypothesis Number Two

Significant Pearson Product-Moment Coefficients of Correlation pertaining to Hypothesis Number Two--that prenatal marital adjustment correlates significantly with postpartum marital adjustment--are summarized in this section.

Entire Sample

Postpartum marital adjustment for the wives was highly correlated with husband postpartum marital adjustment, and with both husband and wife marital adjustment scores on the prenatal test. Correlations between postpartum husband and wife marital adjustment were significant at the .003 level, between postpartum and prenatal marital adjustment wives' scores at the .009 level, and between postpartum marital adjustment wives' scores and prenatal marital 
adjustment husbands' scores at the .004 level. Postpartum marital adjustment for husbands correlated with their prenatal marital adjustment at the .01 level. As husbands' and wives' prenatal marital satisfaction increased, their postpartum marital satisfaction increased also.

Prenatal marital adjustment for wives correlated with their postpartum marital adjustment at the .0009 level and with the couples' postpartum marital adjustment at the .01 level.

Experimental Group

There were two significant correlations within the experimental group pertaining to Hypothesis Number Two. Wives' postpartum marital adjustment correlated with the couples' prenatal marital adjustment at the .09 level of significance. As couple prenatal marital adjustment increased, wives' postpartum martial adjustment scores increased. Wives' and husbands' prenatal marital adjustment correlated with each other at the .08 level of significance, indicating similar marital adjustment for both husband and wife before the baby was born.

\section{Control Group}

Prenatal marital adjustment for the control group couples correlated positively with the couples' postpartum marital adjustment at the .003 level of significance. As 
the couples' prenatal marital adjustment increased, their postpartum marital adjustment increased. Prenatal marital adjustment for wives was positively correlated with couple postpartum marital adjustment at .007 , with husbands' postpartum marital adjustment at .06 , and with wives' postpartum marital adjustment at .0008 . Postpartum marital adjustment for wives correlated with husbands postpartum marital adjustment at .004 . As wives' prenatal and postpartum marital adjustment increased, couple and husband postpartum marital adjustment increased. Wives' and husbands' postpartum marital adjustment correlated with each other. Postpartum marital adjustment for husbands correlated with husband prenatal marital adjustment at .01 and with wife postpartum marital adjustment at .004 . Those husbands who had high prenatal marital adjustment also had high postpartum marital adjustment and, as husbands' postpartum marital adjustment increased, their wives' postpartum marital adjustment increased.

Data Analysis: Hypothesis Number Three

Results pertaining to Hypothesis Number Three--that couples participating together in preparing for the birth of their first child will significantly affect their adjustment to parenthood--are reported in this section (see Tables III and IV). Although t-test results showed no significant differences between the two groups in parenthood adjustment, 
Table III:

Best Parenthood Adjustment:

Two Couples From Experimental and From Control Groups

Compared on All Variables

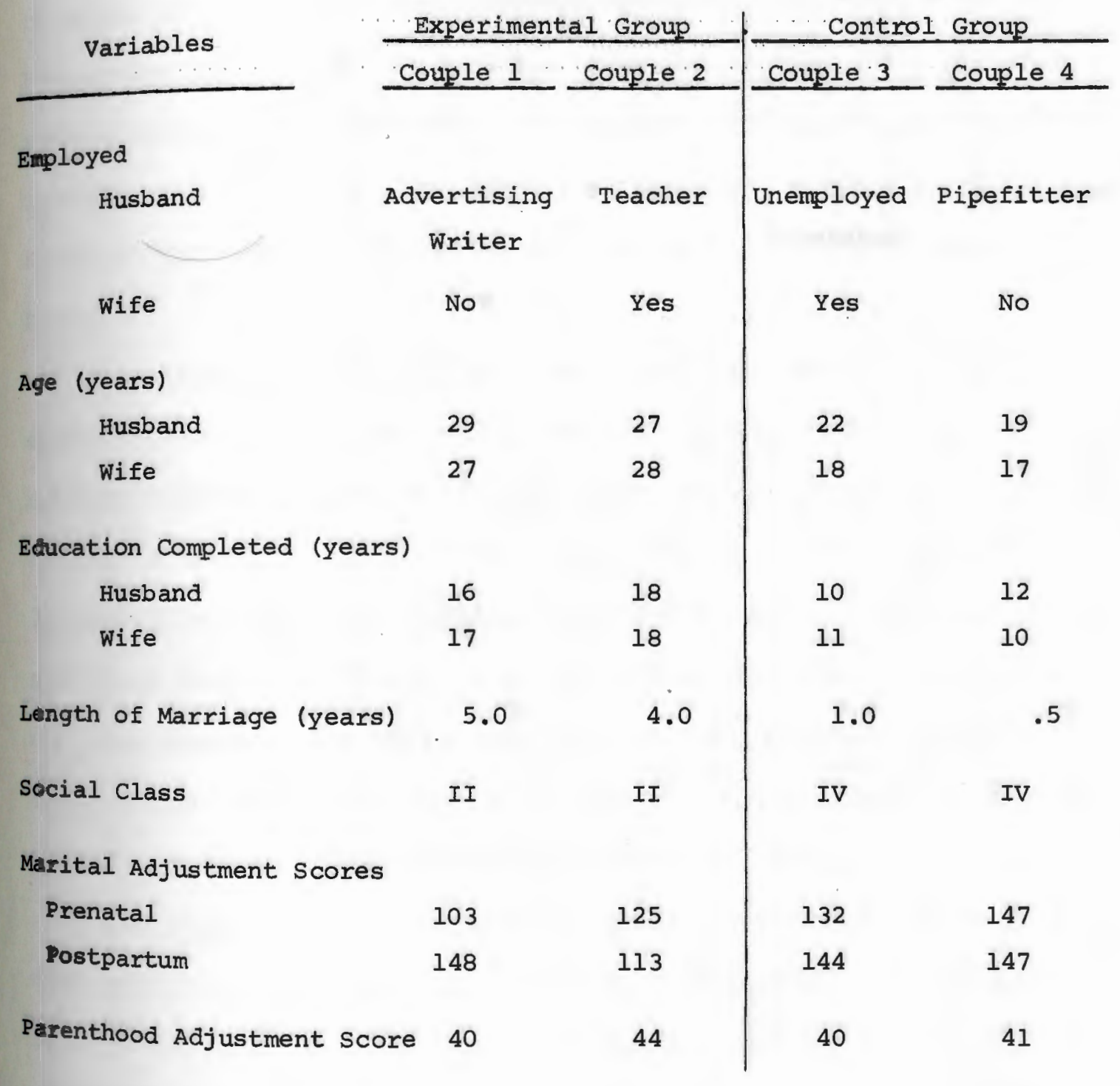


Table IV

Poorest Parenthood Adjustment:

Two Couples From Experimental and From Control Groups

Compared on All variables

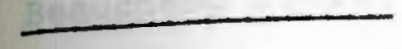

Employed

Husband

Wife

Age (years)

Husband

wife

Education Completed (years)

Husband

Wife

Length of Marriage (years)

24

22

Grocery

Clerk

Yes

Salesma
No

26

25

14

12

16

16

2.75

1.5

Social Class

IV

II

Marital Adjustment scores

Prenatal

Postpartum

132

90

104

102

68

Parenthood Adjustment score 75
Variables

Control Group

Couple 7 Couple 8

Machine Electrician

Operator

Yes

No

25

18

26

18

12

12

12

12

$$
2.0
$$

.75

II

III
129

118

92

114

73

65 
further analysis of the data revealed the following observations.

Couples With Good Parenthood Adjustment Upon examining the data, submitted by the two couples in each sample who received the best scores on the Beauchamp Scale, one correlation exists. All four couples scored high on the marital adjustment scale administered at six weeks postpartum, and three of the four couples scored high on the same scale administered before the babies were born.

Experimental Group. The two couples in the axperimental group who experienced little parenthood adjustment difficulty were all older than the mean age of 27.6 for husbands and 25.7 for wives. They had each been married longer than the mean length of marriage of 3.3 years, one marriage being of four years' duration and the other being of five years. All four are college graduates, and one couple has completed graduate school at the Master's level. Both couples plan to have more children.

Control Group. The two couples who scored best in the control group on the Parenthood Adjustment scale had both been married less than one year. One couple had completed high school, the other had not; both wives had worked before the babies were born and both couples plan to have more children. Both couples were younger than the mean 
age of 23.8 for the husbands and 22.3 for the wives in the control group. Both couples' education level was below the mean of 13 years for the control group, and both couples scored well above the means on both marital adjustment scales.

The experimental couples who scored best on the parenthood adjustment scale differed from the best scoring couples in the control group in the following ways: husbands and wives in the experimental group were considerably older, were more highly educated, belonged to a higher social class, and were married longer than the husbands and wives in the control group. Marital adjustment scores were better for the control group both before and after the babies were born.

Couples With Poor Parenthood Adjustment Experimental Group. Those two. couples from the experimental sample who experienced the most difficult parenthood adjustment as measured by the Beauchamp Scale both showed a drop in their marital adjustment scores at the ix-week postpartum measurement. The drop for one couple was from 132 to 90 ffrom well above the mean of 110.2 to well below the mean of 111.9). Both husbands and wives reported having never cared for a young infant previously, and both reported incomes of $\$ 10,000$ (well below the mean for their group). Both wives had been working as 
secretaries before the births of their babies, and both reported irritability over in-law interference and depression. Control Group. Those two couples from the control group who reported the most difficult parenthood adjustment were dissimilar. Both couples were high school graduates and planned to have more children, and both showed marital adjustment scores at the postpartum measurement close to the mean of 117.4. One couple's mean score was 114 and the other's was 118. One couple's prenatal marital adjustment was low at 92 , and the wife of the other couple reported depression after the baby was born.

In reviewing the data for the two couples in each group who showed poor parenthood adjustment, the differences are not as great as they were for the good parenthood adjustment couples, although the experimental couples were older, more highly educated, and had been married for a longer period of time. Scores on the marital adjustment scales both before and after revealed the experimental couples experiencing slightly greater marital satisfaction. Two of the experimental wives and one control wife had been vorking before the babies were born.

\section{Mean Profiles}

Mean profiles for each sample are presented in Table V. It can be seen from this table that the experimental wives were 3.3 years older than the control wives, and the 
Table V

Comparison of Husbands and Wives in Experimental and Control Groups: Means of Age, Education Completed, Annual Income, Social Class, and Marital and Parenthood Adjustment Scores

Variables

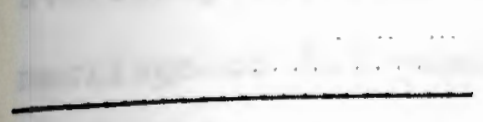

Age (years)

Husbands

Wives
Means of

Experimental Group

$(N=14)$
Means of

Control Group

$(\mathrm{N}=11)$

\section{8}

22.4

Education Completed (years)

Husbands

Wives

Annual Income ${ }^{\dagger}$

(Range)

Social Class

Marital Adjustment Scores

Prenatal

Husbands

Wives

Postpartum

Husbands

Wives
15.0

15.1

$\$ 13,532$

$(\$ 4,500-26,500)$

II

III

$\$ 7,619$

I
13.1

13.0

$(\$ 4,200-11,500)$

$\begin{array}{ll}110.4 & 108.9 \\ 109.7 & 114.5\end{array}$

109.9

115.9

113.5

118.4

Parenthood Adjustment score ${ }^{\dagger \dagger}$

Husbands

Wives
50.6

58.2
49.5

54.5

Four control husbands did not report income, two of whom reported unemployment, so it is difficult to assess income differences between experimental and control groups; wives were not asked to report income.

t+

Low score indicates good adjustment to parenthood. 
experimental husbands were 3.8 years older than the control husbands. The education level of both experimental husbands and wives was $16 \%$ higher than that of both control husbands and wives, with the experimental group averaging at least three years of college education and the control group averaging one year of college education. Mean length of marriage of 3.3 years for the experimental group was $50 \%$ longer than the mean for the control group of 2.2 years. Social status for the experimental group was well within level II, whereas social status for the control group was well within level III.

Ten of the 11 wives in the control group reported having been working before the baby was born, this being $91 \%$ of the sample, whereas 11 of the 14 experimental wives were working before the baby's birth, this being $79 \%$ of the sample.

Looking at the mean scores on the Locke and Wallace Short Marital Adjustment Scale administered before the baby's birth, the husbands' scores for both groups were almost the same, whereas mean score for the control wives was slightly higher (114 compared to 110). The same scale administered at the end of the six-week postpartum period showed a very slight drop for the experimental husbands and a rise of seven points for the control husbands. Both wives' postpartum marital adjustment scores showed a rise, the control group mean from 114 to 117 and the experimental 
group mean from 110 to 113.5. All group mean scores, except the experimental husbands, showed a shift to higher marital satisfaction after the birth of the babies, whereas the experimental husbands' mean remained almost stable, the drop being only one point.

Parenthood adjustment, as measured by Beauchamp's Parenthood Adjustment Scale, indicated the husbands' mean adjustment to be quite similar in both groups, with the experimental mean being 50.6 and the control mean being 49.5. There was a slightly greater difference between the two group means for the wives, with the control mean score at 54.5 and the experimental mean score at 58. Both means indicate a more difficult adjustment on the part of the average wife in each group than that of the average husband. In summarizing the mean profile of each group, the average experimental couple was older, more highly educated, had been married longer, was within a higher social class, and had a considerably higher income than the average control couple. However, the average control couple had better marital adjustment scores both before and after the baby's birth and also scored better on the parenthood adjustment scale. A greater percentage of control wives was working before the babies were born.

\footnotetext{
"Bothersome" Items on the Beauchamp scale The Beauchamp Scale revealed certain "bothersome"
} 
items for both groups of mothers, and certain items were more bothersome to either the experimental group or the control group.

"Physical tiredness or fatigue" was bothersome to $87 \%$ of the experimental mothers and to $73 \%$ of the control mothers. A similar item, "loss of sleep" was bothersome to $82 \%$ of the control mothers and to $71 \%$ of the experimental mothers.

"Worry about personal appearance of wife" was bothersome to $78 \%$ of the experimental mothers and to $73 \%$ of the control mothers, whereas a similar item, "worry about wife's loss of figure" was bothersome to $82 \%$ of the control mothers and to 718 of the experimental mothers.

Financial worries were more bothersome to the control mothers, whose income level was considerably less than that of the experimental mothers. "Reduced income because of wife not working" and "additional expenses for child" were bothersome items to $73 \%$ of the control mothers but to only $50 \%$ of the experimental mothers.

"Excessive confinement to the home" and "feeling 'edgy' or emotionally upset" were bothersome items to $78 \%$ of the experimental mothers, but confinement was bothersome to only 558 of the control mothers and "edginess" was bothersome to 648 of the control mothers. Seventy-one percent (71\%) of the experimental mothers found "interruption of former routine" bothersome, whereas only $45 \%$ of the control 
mothers scored this as a bothersome item.

Fathers also found "loss of sleep" and "physical

tiredness or fatigue" to be bothersome items. Whereas $64 \%$ of the experimental fathers found "loss of sleep" to be bothersome, $45 \%$ of the control fathers found it to be so. In contrast, the same idea expressed as "physical tiredness or fatigue" was found to be bothersome by $73 \%$ of the control fathers and by $57 \%$ of the experimental fathers. It is noted here that wives responded oppositely to these items.

As their wives did, 728 of the control fathers found "reduced income because of wife not working" to be bothersome, whereas it was bothersome to $55 \%$ of the experimental fathers.

One item more bothersome to the experimental fathers and their wives than to the control fathers and their wives was the item "worry about being a good parent": bothersome to $64 \%$ of the experimental fathers and mothers, and bothersome to $45 \%$ of the control fathers and to $54 \%$ of their wives.

Physical and Emotional Difficulties

In reference to the question concerning physical complications during labor and delivery, five of the experimental wives, or $36 \%$, reported complications as follows:

One Caesarian section performed due to the breech position of the baby; 
one mid-forceps delivery, necessary after pushing for five hours;

one labor induced due to toxemia, the patient having been hospitalized for one week previous to delivery (this patient reported having beeen resuscitated in the delivery room);

One induced labor, with no explanation given; and one report of crepitus (creaking of the joints) due to the posterior position of the baby, the patient having pushed three hours (it should be noted here that this is not considered to be a complication by the medical profession).

The control group wives reported only two physical complications, or $18 \%$ of the sample: one Caesarean section and one long labor of 22 hours. The latter case of long labor is not considered a physical complication of labor and delivery by the medical profession because it is difficult to assess when real labor begins.

In reporting physical or emotional difficulties since the birth of the baby, three wives, or $27 \%$ of the control group, reported such difficulties: one infection and two depressions, one with intermittent feelings of padequacy when handling a crying infant. The experimental 
group of mothers, however, reported seven cases of difficulties, or 50\%, since the birth of the baby. Six of these reports were of emotional difficulties such as depression or blues, irritability, difficulty with in-laws, fatigue, and worry about baby's emotional needs. There were two reports of physical complications: one hemorrhoids and one limitation of activities due to a Caesarean section. 


\section{CHAPTER V \\ DISCUSSION}

Results of the marital adjustment scales given prenatal and postpartum, and the parenthood adjustment scale given at six weeks postpartum revealed no significant differences between the scores for the two groups. In fact, mean scores for all groups were similar, as were ranges for all groups.

Although Hypothesis Number Three (that couples participating together in preparing for the birth of their first child will significantly affect their adjustment to parenthood) was not supported by this study, there were some significant findings concerning Hypothesis Number One (that such variables as age, education, social status, length of marriage, prenatal marital adjustment, and postpartum marital adjustment affect adjustment to parenthood) and Hypothesis Number Two (that prenatal marital adjustment correlates significantly with postpartum marital adjustment).

Both husbands and wives in the experimental group were significantly older and more highly educated than those in the control group. Experimental couples were married longer and were in a higher social class than control couples. LeMasters' (1959) crisis research was conducted with middle-class couples with results of "extensive" or "severe" crisis in adjusting to the birth of the first child 
reported by $83 \%$ of the sample. Hobbs' (1957) research on the crisis of the first child reports little crisis at all in his sample of lower-class couples. The results of the present study reveal social status to be a significantly different variable for the two samples, and a significant correlation exists between the experimental group husband and couple parenthood adjustment scores and social status. As social class, determined by Hollingshead's Two Level Index of Social Position (1957), increases, parenthood adjustment for the couple and for the husband becomes increasingly difficult. It could be that social class impact is so great that parenthood preparation given at the end of pregnancy cannot counteract its influences.

Parenthood adjustment scores for the experimental husbands were significantly correlated with several variables: age of husbands and wives, education of wives and length of marriage. These variables correlated negatively with husband parenthood adjustment socres, indicating good adjustment for husbands who were older, whose wives were older and more highly educated, and who had been married longer. There were no similar correlations in the experimental group of wives nor in the control groups of husbands or wives, indicating that age, education, and length of marriage did not correlate significantly with parenthood adjustment for these subgroups.

In looking at the variable of marital satisfaction, 
the results revealed some interesting information within the control group. Negative correlations were found between marital satisfaction and the variables of age, education, and length of marriage, indicating that the older the couple, the higher their education and the longer they were married, the less marital satisfaction was experienced by them. These correlations did not exist within the experimental group. In fact, marital satisfaction for wives of the experimental group correlated significantly with length of marriage and parenthood adjustment of their husbands, and marital satisfaction for the husbands correlated significantly with age of their wives, indicating that wives married longer experienced higher marital satisfaction, as did husbands with older wives. That is, within each group, marital satisfaction correlated differently. It would seem that control group couples, with a significantly shorter mean length of marriage, were not experiencing as much marital satisfaction as experimental group couples who had been married longer.

There was a tendency within the control group to experience less satisfactory marital adjustment as they were married longer, if their education level was beyond the mean of 13 years, whereas the older wives in the experimental group tended to have husbands who adjusted better to parenthood and who experienced greater marital satisfaction. Experimental wives' age also correlated with better couple 
renthood adjustment, indicating older wives having some influence on the couples' adjustment to parenthood.

one conclusion might be drawn from the significant differences in age, education, length of marriage, and social class between the two groups. That is, there may be a tendency toward self-selection in terms of these variables working here. Those who participate in these CEA of Rhode Island childbirth preparation classes are more likely to be older, more highly educated, married longer, and of a higher social class than those couples who do not attend such classes. That is, the experimental group may be drawn from a population that is more extended, more mobile, with a greater range of life experience than the population from which the control group was drawn. If this is not an artifact of sampling, then considerable attention should be given to the implications of homogeneity in background haracteristics.

Another possibility which might have contributed to the experimental group's less satisfactory adjustment to parenthood may be the element of expectation. Perhaps those couples who participate in childbirth preparation classes expect the experience of childbirth to be more exciting, more fulfilling, than it possibly can be or perhaps, on the other hand, they expect to encounter problems in childbirth and having a new baby and, in a "self-fulfilling prophecy" vein, they do experience trouble. Either expectation can be 
difficult to handle. Perhaps couples in a lower social class expect less of the childbirth experience, accept it as just another part of life and do not look for a great mperience or fulfillment. One question that arises is whether or not different factors operate to contribute to the parenthood adjustment of different groups of couples, one which seeks preparation for childbirth and one which does not.

LeMasters' (1957) research indicated that professional women experience greater crisis in adjusting to the birth of the first child. Although the questionnaire did not ask specifically for the wife's occupation, five of the experimental wives were professionally employed and two others reported working as secretaries, whereas there were two professional women in the control group. That is, $36 \%$ of the experimental wives were working as professionals and $18 \%$ of the control wives were working as professionals. These professional women may have had more difficulty adjusting to parenthood than the non-professional women. Also, since the experimental group mean length of marriage was $50 \%$ longer than that of the control group, the experimental wives may have been working considerably longer than the control wives. A baby who interrupts a well established routine for a couple and for a working wife may be more of an interruption than a baby who arrives within the first or second year of marriage to a woman whose work 
may not be particularly meaningful to her.

This factor could be supported by the response to Beauchamp item 4, "excessive confinement to the home," poported bothersome to $78 \%$ of the experimental mothers and to just $55 \%$ of the control mothers. Perhaps having been independent for two years or more, free to come and go as one chooses, a woman feels quite bothered by excessive confinement to the home. Perhaps with little child care axperience, she expects that a baby will not take as much of her time as it actually does, that she will be able to manage easily with a third member in her household. Perhaps a woman who has had more experience with infant care and less experience with independence knows that she will be confined to her home for a certain period of time during the infant's early life and is not bothered by such confinement. The same analysis might be applied to item 8 , "Aterruption of former routine" "bothersome to $7.1 \%$ of the experimental mothers but to only 45 \% of the control mothers.

In analyzing the items on the Beauchamp scale, it became evident that measurement is quantitative but not necessarily qualitative. That is, to be bothered by one item might be more troublesome to a couple than to be troubled by another item, equally weighted on the scale. For instance, economic stress is probably the major area of Mstress for American families today. Items 21 and 25 , 
"reduced income because of wife not working" and "additional expenses for child," were two items bothersome to almost $73 \%$ of the control parents but to only $53 \%$ of the experimental parents. This bothersome factor may be causing more stress in the life of this family than is indicated by their score. other items in the Beauchamp scale bothersome to couples in this study suggest implications concerning individual expectations about parenthood. Items 5 and 28, "loss of sleep" and "physical tiredness or fatigue," seem to be similar items, but loss of sleep was more bothersome to control mothers and physical fatigue was more bothersome to the experimental mothers. It could be that the experimental pothers knew they would lose sleep but did not understand beforehand what incredible physical fatigue they would encounter. Perhaps the control mothers did not anticipate how much sleep they would lose and were more bothered by being up many times during the night.

Fathers' responses tended to be opposite chose of their wives on these items, with experimental fathers more bothered by "loss of sleep" and control fathers more Pothered by "physical tiredness or fatigue." This raises the possibility that the experimental fathers, who were Involved in the labor and delivery experience, may also be more involved in the care of their newborns. Perhaps they are getting up for late night feedings, "walking the floor," or getting up early with their babies. 
children and the child's effect on the parents.

Some of these findings suggest that the Beauchamp scale does not measure adequately the degree of difficulty new fathers and mothers might be having in adjusting to their infants during the six-week postpartum period. Since so many variables are involved in marriage and family (such as age, education, social class, and length of marriage) and so many abstract variables (such as expectations, class differences, hopes, ideas, and ideals), it might be bmpossible to construct a scale measuring the effect of thildbirth preparation on postpartum parenthood adjustment or, at least, perhaps the Beauchamp scale cannot measure such a variable as experience in childbirth preparation class .

The fact that $50 \%$ of the experimental mothers zeported some kind of emotional or physical complication since the birth of the baby is an interesting and puzzling one. There has been some conjecture that prepared mothers who expect an exciting, fulfilling experience during childbirth are treated with disregard and disrespect Poncerning their desire to play an important role in this very important experience in their lives by hospital staff and are left with feelings of emotional distress and disappointment which carry over into the postpartum period. In fact, the medical field is now considering postpartum epression or blues to be a natural, expected part of the 
childbirth experience, rather than an unusual occurrence experienced by a relatively small number of women (Arms, 1975).

The present study indicates, however, that this kind of childbirth preparation based on the Lamaze method does not include adequate preparation for postpartum adjustment difficulties and that there is a great need for such preparation to be incorporated into the program. Perhaps the instructor might visit with the new family to talk about adjustment problems, to make helpful suggestions concerning fatigue, confinement, interruption of routine, personal appearance, babysitting, or other such difficulties. Perhaps classes or meetings after the babies are born to discuss problems and expectations as a group of new parents could be held. When one is feeling depressed, it sometimes helps to talk to others who are having the same difficulty in order to discover that one is not alone with feelings of motional distress. And, perhaps more importantly, discussions of expected problems during the postpartum period could take place in the prenatal preparation classes. These discussions could be led by new parents who have recently experienced postpartum adjustment and are willing to share their experiences with those expectant parents who are about ready to undertake the same experience. Gordon's (1961) findings list fourteen suggestions for couples who are expecting their first baby: (1) mother- 
hood is learned, it is not natural; (2) ask for help when you need it; (3) befriend couples with young children; (4) overlook less important tasks; (5) do not plan to get around too quickly after the baby's birth; (6) do not be verconcerned about appearances when more important things need to be done; (7) get adequate rest; (8) do not nurse older relatives; (9) talk about your problems with your spouse, family, and friends with children; (10) maintain outside interests; (11) learn to drive; (12) find a suitable babysitter before delivery; (13) engage a physician or pediatrician; and (14) become interested in your spouse's goals and discuss them.

Although Gordon's (1961) recommendations are made for mothers, preparation classes might emphasize these points for fathers and mothers, as well as those issues directly involved with the labor and delivery experience.

In the present study, those mothers experiencing the most difficulty tended to be college educated, married longer than two years, employed (some as professionals), and pelonging to a high social class (most were in either level I or II of Hollingshead's possible I-V range). Perhaps these women could be identified as "high risk" mothers and could be better prepared for parenthood by a childbirth preparation program that tries to consider the particular difficulties this group of women might have. Fathers in this study tended to have less difficulty adjusting to 
parenthood than did mothers in either of the two groups. Perhaps preparation classes could investigate how fathers could best help their wives during this difficult transition period. Included in the preparation program might be constructive suggestions on how fathers could more share with their wives the burden of early infant care.

\section{Significant Differences}

In summarizing t-ratio results, the experimental group was significantly older, more highly educated, had been married longer, and belonged to a higher social class than the control group. It should be noted here that the experimental husbands' income level was considerably higher than that of the control husbands although, because not all control husbands reported income, it was not possible to accurately compare the two. Significant differences between the two groups were as follows:

1. There was a significant age difference between the two groups of husbands and the two groups of wives, the experimental group of husbands and wives being older.

2. There was a significant difference between the education levels of the two groups of wives and husbands, with the experimental wives and husbands more highly educated than the control wives and husbands. The 
difference between the education levels of the two groups of wives was more statistically significant than that of the two groups of husbands.

3. There was a significant difference between the social class levels of the two groups of couples, the experimental group being in a higher social class than the control group.

4. There was a near significant difference between the lengths of marriage for the two groups, the experimental group mean length of marriage being $50 \%$ greater than that of the control group.

Significant Findings

Findings related to marital satisfaction and parenthood adjustment for the two groups can be summarized as follows:

1. Couples who scored high on prenatal marital satisfaction also scored high on postpartum marital satisfaction.

2. Couples who experienced greater marital satisfaction also experienced better parenthood adjustment.

3. Husbands who experienced high marital 
satisfaction showed high parenthood adjustment.

4. Wives who experienced high postpartum marital satisfaction tended to adjust better to parenthood.

5. Couples who were more highly educated experienced more marital adjustment difficulties.

6. Wives in lower social levels experienced greater marital satisfaction.

7. Husbands and wives experienced similar parenthood adjustment as well as prenatal and postpartum marital satisfaction, whether the scores were high or low.

8. Within the experimental group, husbands who adjusted well to parenthood tended to be older, to have been married longer to wives-whose educational level was higher, and to belong to a higher social class.

9. Experimental wives who had been married longer experienced greater prenatal marital adjustment, but there was no significant correlation between length of marriage and wives' postpartum marital adjustment.

10. Within the control group, marital satisfac- 
tion tended to decrease as length of marriage increased, husband's age increased, and wife's education level rose.

11. Younger control wives and husbands in lower social classes with less education and shorter marriages tended to score higher on marital satisfaction.

\section{"Bothersome" Items}

The most bothersome items on the Beauchamp Parenthood Adjustment Scale can be summarized as follows:

1. Experimental mothers tended to be most bothered by excessive confinement to the home, physical tiredness or fatigue, feeling "edgy" or emotionally upset, worry about personal appearance, and interruption of former routine.

2. Control mothers tended to be most bothered by loss of sleep, worry about wife's loss of figure, reduced income because of wife's not working, and additional expenses for the child.

3. Experimental fathers tended to be most bothered by loss of sleep and worry about being a good parent.

4. Control fathers tended to be most bothered 
by physical tiredness or fatigue and reduced income because of wife's not working. Because of the limited number of subjects and the impossibility of matching the samples for such variables as age, education, length of marriage, and social class, it is possible only to look at tendencies within each group.

\section{Suggestions for Future Research}

At least three more studies might come out of the present study, each study with a considerably larger, more representative sampling. One study could be conducted using a large random sample of couples in childbirth preparation classes, with a control group closely matched for age, education, length of marriage, and social class.

Another two studies might investigate childbirth preparation effects on postpartum parenthood adjustment within certain social classes, such as comparing two middle class, college educated groups, and another comparison of two lower class, non-college educated groups. The combined results of these three studies may enable researchers to more closely determine what specific variables contribute to parenthood adjustment.

Future research might include questions pertaining to new parents' expectations and hopes concerning parenthood and the experience of adding an infant to a household, to letermine whether social class, education, age, or length of 
marriage may influence and contribute to one's expectations of parenthood. Whether or not the wife is a professional or non-professional, her length of employment and professional aspirations would be other necessary information when conducting a study such as the present one. LeMasters' (1957) findings that professional women experienced more crisis with the first child lead the present researcher to believe that this is an important factor in determining variables which contribute to parenthood adjustment. Finally, there have been studies investigating the effects of childbirth preparation: on labor and delivery (Tanzer, 1968; Miller, 1971; Huttel et al., 1972), but this has been the first investigation into the effect of childbirth preparation upon postpartum parenthood adjustment at the end of six weeks. The present findings suggest that expectations, hopes, professionalism of the wives, and disproportionate troubles contribute to parenthood adjustment. Perhaps a scale designed to measure some of these variables could be developed to better measure parenthood adjustment. This scale might also attempt to measure the degree of satisfaction within the couple relationship since they have become parents. 


\section{CHAPTER VI}

\section{SUMMARY}

This study examined the effect of childbirth preparation classes on parenthood adjustment at the end of the six-week postpartum period by comparing a group of 14 couples who had attended childbirth preparation classes, given by the Childbirth Education Association of Rhode Island, with a group of 11 couples who had not participated in any kind of childbirth preparation.

Couples for the experimental group were recruited through the Childbirth Education Association of Rhode Island and the control group of couples was recruited through local obstetricians. Of the 42 couple names submitted for both groups, 25 couples completed the requirements for participation by completing two questionnaires: (1) the Locke and Wallace Short Marital Adjustment Scale and (2) Beauchamp's Parenthood Adjustment Scale and the Locke and Wallace Scale repeated. Additional demographic data were submitted on the questionnaires.

Although there were no significant differences in the marital satisfaction scores and the parenthood adjustment scores between the two groups, the differences in such variables as age, education, social class, and length of marriage between the two groups contributed to some significant findings. 
There is no doubt: that parenthood will continue to be an important life stage for American couples of the future and that early parenthood will continue to be a difficult time of adjustment for the couple involved, as well as an important time in the life space of the baby involved. There is, therefore, a great demand for better programs of parenthood preparation, programs that extend far beyond the labor and delivery rooms. The Lamaze method of childbirth preparation begins the preparation for parenting, but this preparation must be extended farther into the life space of American families today. 


\section{BIBLIOGRAPHY}

Arms, S. Immaculate Deception. San Francisco Book Co./ Houghton Mifflin Co., Boston, Mass., 1975.

Arnstein, H. The crisis of becoming a father. Sexual Behavior, 1972,2 (No. 4), 42-47.

Beauchamp, D. Parenthood as crisis: An additional study. Unpublished Master's thesis, University of North Dakota, 1968.

Benson, L. Fatherhood. Random House, New York, N.Y., 1968.

Bibring et al. A study of the psychological process in pregnancy and the earliest mother-child relations. Psychoanalytic Study of the Child, 1961, 16.

Biller, H. Paternal Deprivation. D.C. Heath and Co., Lexington, Mass., 1974.

Biller, H. and Meredith, D. Father Power. David McKay, New York, N.Y., 1975.

Blood, R.O. The Family. Free Press, New York, N.Y., 1972.

Brenton, M. The American Male. Fawcett Publications, Greenwich, Conn., 1966.

Chertok, I. Motherhood and Personality. Lippincott, Philadelphia, Pa., 1969.

Davids, A. and Rosengren, W.R. Social stability and psychological adjustment during pregnancy. Psychosomatic Medicine, 1962, 3, 203-207.

Davis, C.D. and Morrone, F.A. An effective evaluation of a prepared childbirth program. American Journal of Obstetrics and Gynecology, $196 \overline{2,84}$ (No. 9), 11961206 .

Dyer, E.D. Parenthood as crisis: A restudy. Marriage and Family Living, 1963, 25, 196-207.

Erikson, E. Childhood and Society. W.W. Norton, New York, N.Y., 1963 .

Feldman, H. Development of the husband-wife relationship. Mimeographed grant application E-288, undated. 
Feldman, H. and Rogoff, M. Correlates of changes in marital satisfaction with the birth of the first child. Mimeographed, Department of Child Development and Family Relationships, Cornell University, Ithaca, N.Y., undated.

Gordon et al. Factors in postpartum emotional adjustment. obstetrics and Gynecology, 1965, 25, 158-166.

Hartman, A.A. and Nicolay, R.C. Sexually deviant behavior in expectant fathers. Journal of Abnormal Psychology, 1966, 71, 232-234. Hill, R. Families Under Stress. Harper and Brothers, New

Hobbs, D.F. Parenthood as crisis: A third study. Journal of Marriage and the Family, 1965, 27, 367-372.

Hobbs, D.F. Transition to parenthood: A replication and extension. Journal of Marriage and the Family, $1968,30,413-417$.

Hollingshead, A.B. Two Factor Index of Social Position. Published by the author, New Haven, Conn., 1965; Yale Station, 1957.

Huttel, F.A. et al. A quantitative evaulation of psychoprophylaxsis in childbirth. Journal of Psychosomatic Research, $1972,16,81-92$.

Jacoby, A.P. Transition to parenthood: A reassessment. Journal of Marriage and the Family, 1969, 31, 720727.

Rirkpatrick, S.W. Adjustment to parenthood: A structural model. Ph.D. thesis, Ohio State University, 1971. University Microfilms, Ann Arbor, Mich.

Lake, A. Three for the seesaw: How a first baby changes a marriage. Redbook, April 1974, 99, 150-152.

Larsen, V. Stresses of the childbearing years. American Journal of Public Health, 1966, 56, 32-36.

LeMasters, E.E. Parenthood as crisis. Marriage and Family Living, 1957, 19, 352-355.

Miebenberg, B. Expectant fathers. American Journal of Orthopsychiatry, $1967,37,358-359$. 
Locke, H.J. and Wallace, K.M. Short marital adjustment and prediction tests: Their reliability and validity. Marriage and Family Living, 1959, 21 (No. 3), 251255.

Lopata, H.Z. The secondary features of a primary relationship. Human Organization, 1965, 24, 116-123.

Lynn, D.B. The Father, His Role in Child Development. Brooks/Cole Publishing Co., Monterey, Cal., 1974 .

Mace, D. Can a baby break up a marriage? McCalls, July 1958.

Meyerowitz, J.H. Satisfaction during pregnancy. Journal of Marriage and the Family, 1970, 32, 38-42.

Meyerowitz, J.H. and Feldman, H. Transition to parenthood. Psychiatric Research Report, 1966, 22, 78-84.

Miller, J.S. Childbirth: Progress in dignity. Journal of Humanistic Psychology, 1971, 11, 85-92.

Parke, R.D. and O'Leary, S. Father-mother-infant

interaction in the newborn period, in $\mathrm{K}$. Riegel and J. Meacham (eds.), Determinants of Behavioral Development, II, 1974 .

Rossi, A.S. Transition to parenthood. Journal of Marriage and the Family. 1968, 30, 26-39.

Simonowitz, H. Liberation and postpartum adjustment. Unpublished Master's thesis, University of Rhode Island, 1974.

Tanzer, D.R. Natural childbirth: Pain or peak experience? Psychology Today, October 1968.

Wainwright, W.H. Fatherhood as a precipitant of mental illness. American Journal of Psychiatry, 1966, 123, $40-44$.

Wenner, N. et al. Emotional problems in pregnancy. Psychiatry, 1969, 32, 389-410.

Wilson, G. and Ryland, G. Social Group Work Practice. Houghton Mifflin Co., Boston, Mass., 1949.

Winch, R.F. Basic societal functions, in R.F. Winch and L.W. Goodman (eds.), Selected Studies in Marriage and the Family. Holt, Rinehart, and Winston, New 
York, 1968. 
Appendixes 
First Mailing

Prenatal Letter and Questionnaire 
University of Rhode Island Kingston, Rhode Island January 15, 1975

Dear

Thank you for agreeing to participate in my research concerning the first baby.

Enclosed you will find the questionnaire to be filled out immediately. It is very important that you complete it before the baby is born and that you return it to me as soon as possible. Please complete the questionnaires independently of each other. I have enclosed a selfaddressed stamped envelope for your convenience.

Six weeks after your baby is born, you will receive the second questionnaire which will be completed anonymously. Please remember to let me know when your baby is born. This is a very exciting event in your lives and I wish you the very best of everything. Have a great baby! sincerely yours,

Joyce Anderson

Graduate Student

$272-1979$

George T. Fitzelle, Ph.D., Faculty Advisor 
Name

Age

Number of years married

Education: Completed high school

Attended college.

years

Completed college

Graduate school years

Graduate degree

Occupation

Yearly income

Have you ever cared for a young infant?

Frequently

Infrequently

Never

Do you and your wife plan to have additional children?

Check the dot on the scale line below which best describes the degree of happiness, everything considered, of your present marriage. The middle point, "happy," represents the degree of happiness which most people get from marriage, and the scale gradually ranges on one side to those few who are very unhappy in marriage and, on the other, to those few who experience extreme joy in marriage.

\begin{tabular}{lcc}
\hline Very & Happy & Perfectly \\
Unhappy & Happy
\end{tabular}

State the approximate extent of agreement or disagreement between you and your mate on the following items. Please check each column or space.

$$
\begin{aligned}
A A & =\text { Always Agree } \\
\text { AAA } & =\text { Almost Always Agree } \\
O D & =\text { Occasionally Disagree }
\end{aligned}
$$

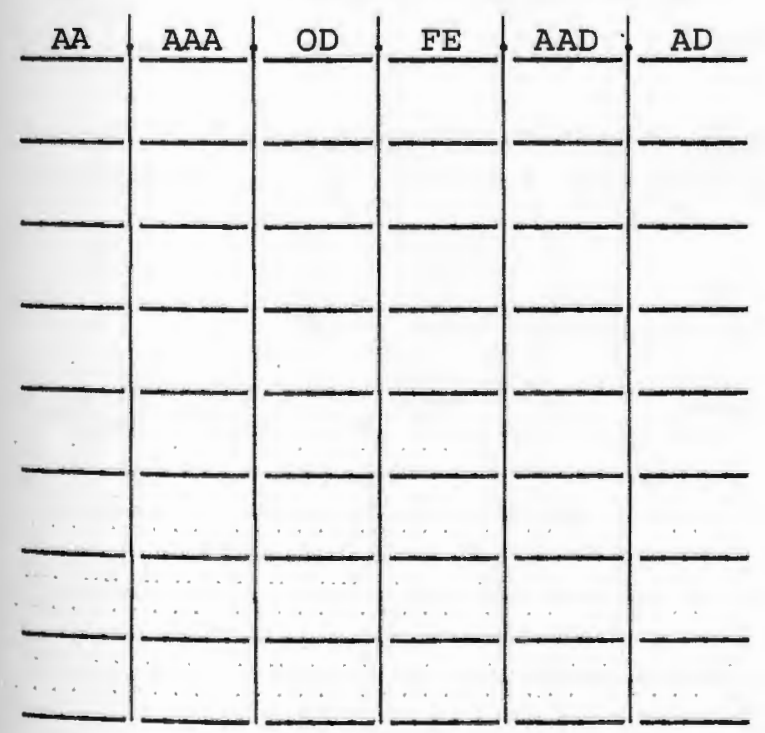

$$
\begin{aligned}
F D & =\text { Frequently Disagree } \\
A A D & =\text { Almost Always Disagree } \\
A D & =\text { Always Disagree }
\end{aligned}
$$

1. Handling family finances

2. Matters of recreation

3. Demonstrations of affection

4. Friends

5. Sex relations

6. Conventionality (right, good, or proper conduct)

7. Philosophy of life

8. Ways of dealing with in-laws 
9. When disagreements arise, they usually result in a.......husband giving in. wife giving in. agreement by mutual give and take. (Check only one)

10. Do you and your mate engage in outside interests together?

All of them
Some of them
Very few of them
None of them (Check only one)

11. In leisure time, do you generally prefer to be "on the go"? to stay at home? (Check only one)

12. Do you ever wish you had not married?

\begin{tabular}{l} 
Frequently \\
\hline Occasionally \\
\hline Rarely \\
\hline Never
\end{tabular}

13. If you had your life to live over, do you think you would marry the same person? marry a different person? not marry at all? (Check only one)

14. Do you confide in your mate? Almost never Rarely In most things In everything (Check only one) 
Name

Age

Education: Completed high school

Attended college

years

Completed college

Graduate school

years

Graduate degree

Are you working now or were you working before this pregnancy?

Have you ever cared for a young infant?

Frequently

Infrequently

Never

Have you experienced any physical complications during this pregnancy?

If so, please describe

Have you ever had any serious physical or emotional illness?

If so, please describe

Has there been any reoccurrence during this pregnancy?

Check the dot on the scale line below which best describes the degree of happiness, everything considered, of your present marriage. The middle point, "happy," represents the degree of happiness which most people get from marriage, and the scale gradually ranges on one side to those few who are very unhappy in marriage and, on the other, to those few who experience extreme joy in marriage.

\begin{tabular}{lcc}
\hline Very & Happy & Perfectly \\
Unhappy & Happy
\end{tabular}

State the approximate extent of agreement or disagreement between you and your mate on the following items. Please check each column or space.
$A A=$ Always Agree
AAA $=$ Almost Always Agree
$O D=$ Occasionally Disagree

$\mathrm{FD}=$ Frequently Disagree

$A A D=A$ lmost Always Disagree

$A D=A$ lways Disagree

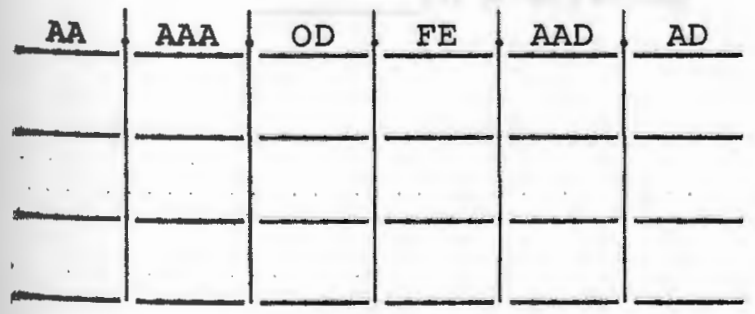

1. Handling family finances

2. Matters of recreation

3. Demonstrations of affection 


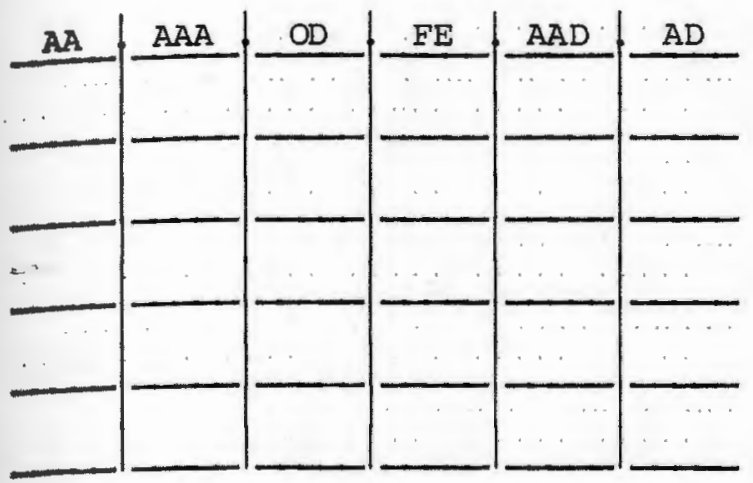

4. Friends

5. Sex relations

6. Conventionality (right, good, or proper conduct)

7. Philosophy of life

8. Ways of dealing with in-laws

9. When disagreements arise, they usually result in husband giving in. wife giving in. agreement by mutual give and take. (Check only one)

10. Do you and your mate engage in outside interests together?

All of them
Some of them
Very few of them
None of them

(Check only one)

11. In leisure time, do you generally prefer to be "on the go"?

- to stay at home? (Check only one)

12. Do you ever wish you had not married?

Frequently

\begin{tabular}{l} 
Frequently \\
\hline Occasionally \\
\hline Rarely \\
\hline Never
\end{tabular}

13. If you had your life to live over, do you think you would marry the same person? marry a different person? not marry at all? (Check only one)

14. Do you confide in your mate? Almost never Rarely In most things In everything (Check only one) 
Second Mailing

Postpartum Letter and Questionnaire 
University of Rhode Island Kingston, Rhode Island

March 1, 1975

Dear

Here is the second set of questionnaires for you to complete six weeks after the birth of your baby. It is extremely important that you complete these questionnaires on this day, , and return them immediately.

I am enclosing two stamped envelopes to insure complete privacy for each set of questionnaires. Please complete them independently, do not write your name on them, and mail them in the envelopes provided.

I want to thank you very much for having participated in this study. Without you, I couldn't have done it. Congratulations on the birth of your baby and good luck with your new family. You will be hearing from me again when I have completed my thesis. Again--thank you.

Sincerely yours,

Joyce Anderson

Graduate Student

George T. Fitzelle, Ph.D., Faculty Advisor 
HUSBAND

Have you experienced any physical or emotional difficulties since the birth of your baby? If so, please describe

Have you ever participated in any courses which you feel helped you prepare for parenthood? If so, please describe

The following is a list of possible difficulties that may have become bothersome following the birth of your child. Please check the column that indicates how bothered you are or have been by each item since your child was born.

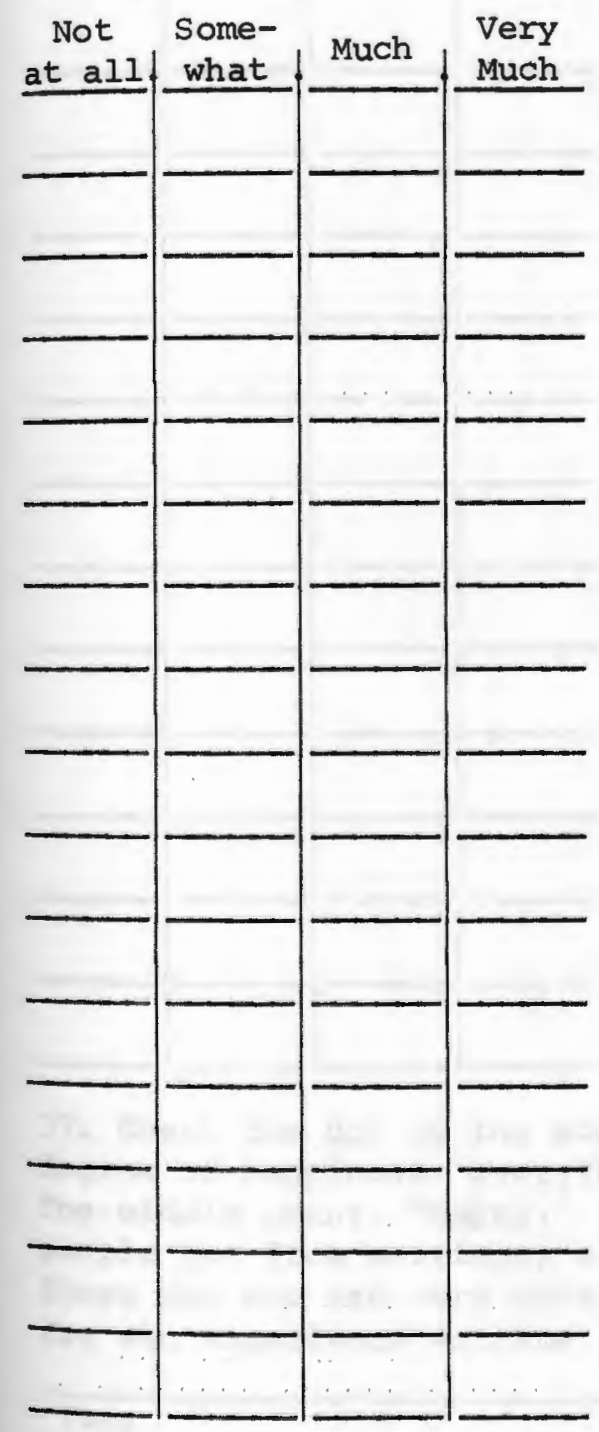

1. My wife showing too little concern for the baby

2. Interference from in-laws

3. Worry about the personal appearance of wife

4. Excessive confinement to the home

5. Loss of sleep

6. Wife showing too much attention to baby

7. Inability to keep up with the work

8. Interruption of former routine

9. Disturbed about feelings I have toward baby

10. Housekeeping not as it should be

11. Decreased sexual responsiveness of self

12. Wife showing too little attention to baby

13. Feeling more "distant" from my wife

14. Being unable to sleep after going to bed

15. Having to change plans we had before baby's birth

16. Being unable to give wife previous amount of affection 


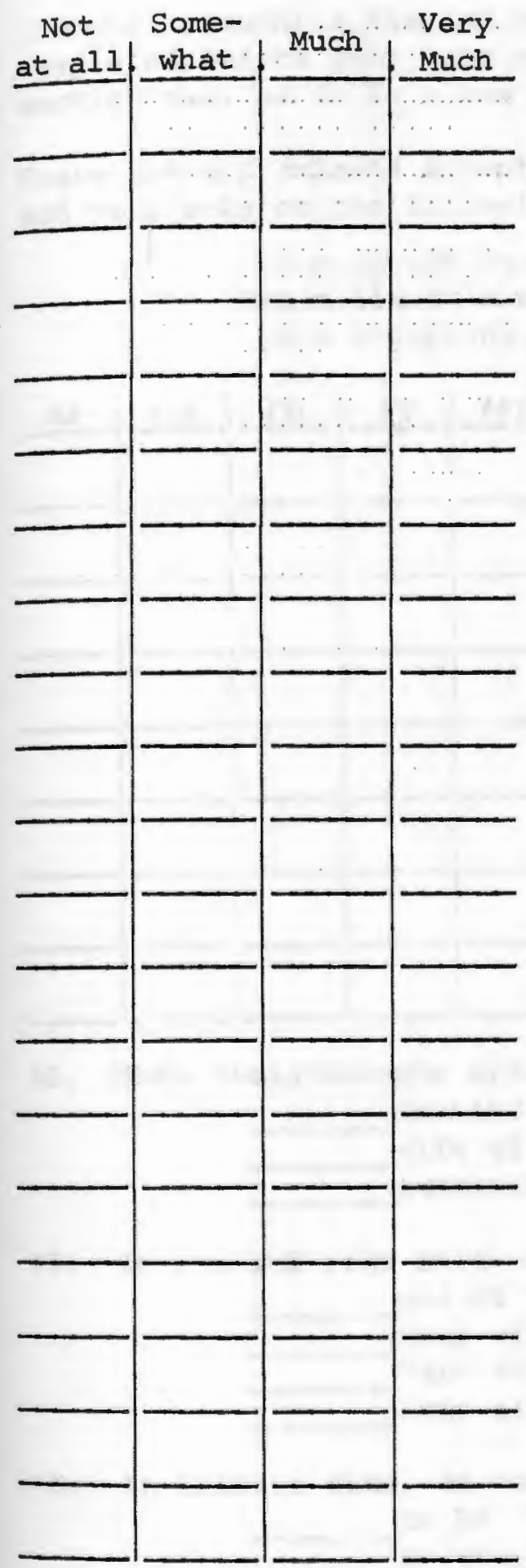

17. Meals being off schedule

18. Inadequate leisure time to do things that please us

19. Being unable to care for baby as I would like to

20. Decline in sexual responsiveness of wife

21. Reduced income because of wife not working

22. Feelings of being alone

23. Reduced feelings of privacy

24. Worry about being a good parent

25. Additional expenses for child

26. Worry about wife's loss of figure

27. Interference with social life

28. Physical tiredness or fatigue

29. Unhappiness with new parent role

30. Wife's giving up career

31. Worry about first babysitter

32. Being unprepared for time and work baby involves

33. Worry about second pregnancy in near future

34. Not being able to forget the baby for a few hours

35. Feeling "edgy" or emotionally upset

36. Wife not the kind of parent I expected

37. Check the dot on the scale line below which best describes the degree of happiness, everything considered, of your present marriage. The middle point, "happy," represents the degree of happiness which most people get from marriage, and the scale gradually ranges on one side to those few who are very unhappy in marriage and, on the other, to those few who experience extreme joy in marriage. 
You will recognize the following questions from the questionnaire you completed before your baby was born. Would you kindly complete this section now, as it is a new period in your life as a married couple?

State the approximate extent of agreement or disagreement between you and your mate on the following items. Please check each column or space.

$$
\begin{aligned}
A A & =\text { Always Agree } & \text { FD } & =\text { Frequently Disagree } \\
A A A & =\text { Almost Always Agree } & A A D & =\text { Almost Always Disagree } \\
O D & =\text { Occasionally Disagree } & A D & =\text { Always Disagree }
\end{aligned}
$$

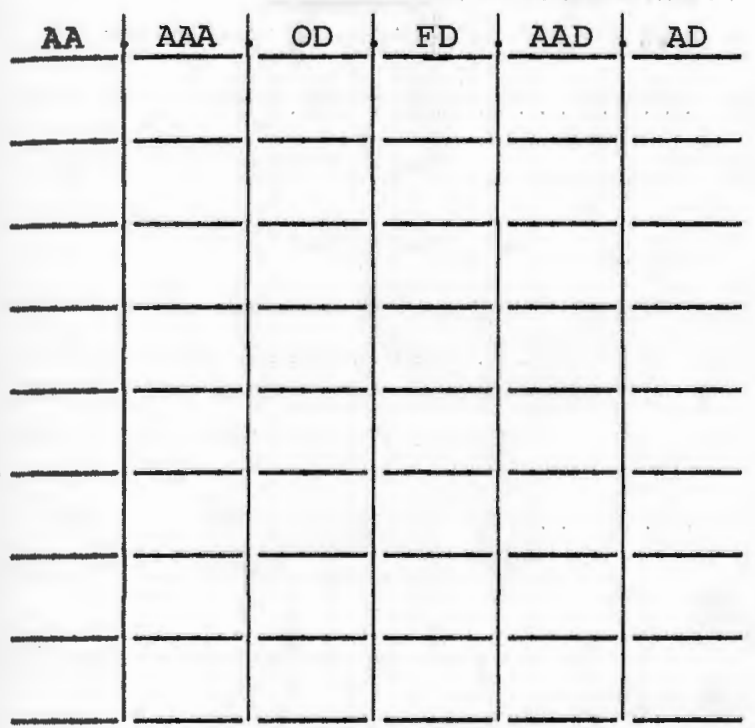

38. Handling family finances

39. Matters of recreation

40. Demonstrations of affection

41. Friends

42. Sex relations

43. Conventionality (right, good, or proper conduct)

44. Philosophy of life

45. Ways of dealing with in-laws

46. When disagreements arise, they usually result in husband giving in. wife giving in. agreement by mutual give and take. (Check only one)

47. Do you and your mate engage in outside interests together?

All of them

Some of them

Very few of them

None of them (Check only one)

48. In leisure time, do you generally prefer

to be "on the go"?

to stay at home? (Check only one)

49. Do you ever wish you had not married?

Frequently

occasionally

Rarely

Never 
50. If you had your life to live over, do you think you would marry the same person? marry a different person? not marry at all?

(Check only one)

51. Do you confide in your mate?

Almost never
Rarely
In most things
In everything (Check only one)


WIFE

Did you experience any physical complications during your labor and delivery? If so, please describe

Have you experienced any physical or emotional difficulties since the birth of your baby? If so, please describe

Have you ever participated in any courses which you feel helped you prepare for parenthood? If so, please describe

The following is a list of possible difficulties that may have become bothersome following the birth of your child. Please check the column that indicates how bothered you are or have been by each item since your child was born.

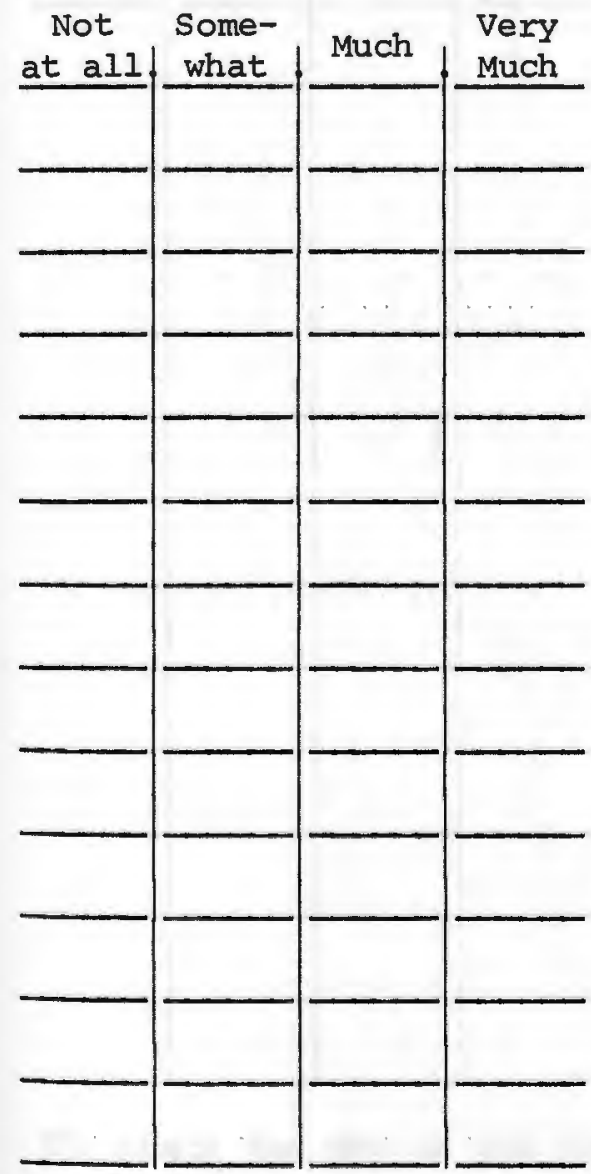

1. My husband showing too little concern for the baby

2. Interference from in-laws

3. Worry about personal appearance

4. Excessive confinement to the home

5. Loss of sleep

6. Husband showing too much attention to baby

7. Inability to keep up with the work

8. Interruption of former routine

9. Disturbed about feelings I have toward baby

10. Housekeeping not as it should be

11. Decreased sexual responsiveness of self

12. Husband showing too little attention to baby

13. Feeling more "distant" from my husband 


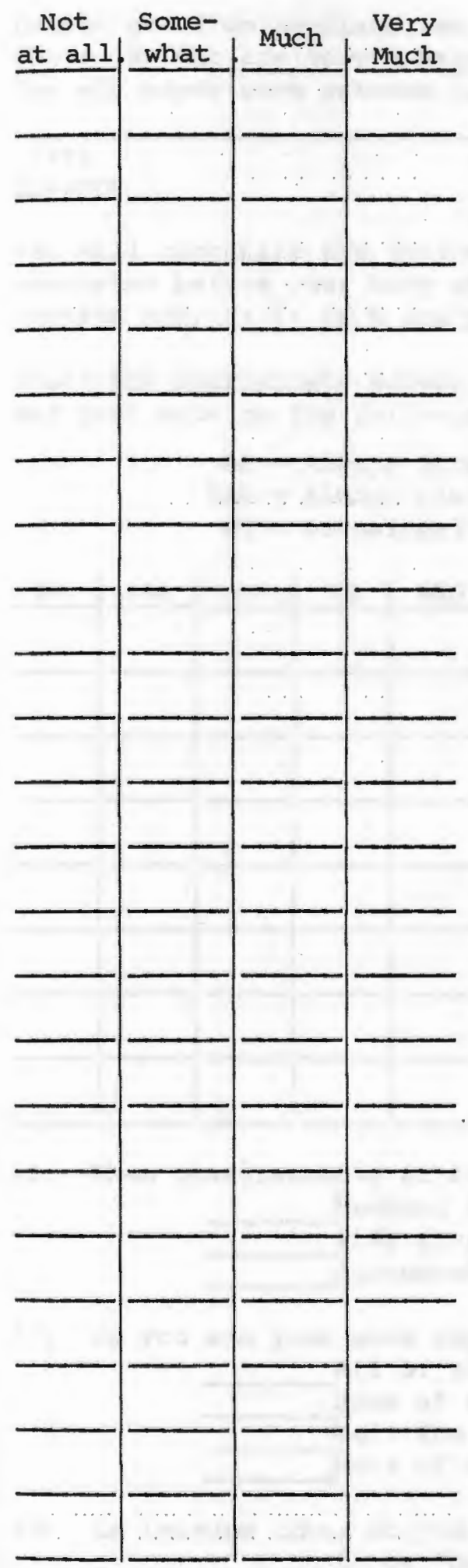

14. Being unable to sleep after going to bed

15. Having to change plans we had before baby's birth

16. Being unable to give husband previous amount of affection

17. Meals being off schedule

18. Inadequate leisure time to do things that please us

19. Being unable to care for baby as I would like to

20. Decline in sexual responsiveness of husband

21. Reduced income because of wife not working

22. Feelings of being alone

23. Reduced feelings of privacy

24. Worry about being a good parent

25. Additional expenses for child

26. Worry about wife's loss of figure

27. Interference with social life

28. Physical tiredness or fatigue

29. Unhappiness with new parent role

30. Wife's giving up career

31. Worry about first babysitter

32. Being unprepared for time and work baby involves

33. Worry about second pregnancy in near future

34. Not being able to forget the baby for $a$ few hours

35. Feeling "edgy" or emotionally upset

36. Husband not the kind of parent I expected

37. Check the dot on the scale line below which best describes the degree of happiness, everything considered, of your present marriage. The middle point, "happy," represents the degree of happiness which most 
people get from marriage, and the scale gradually ranges on one side to those few who are very unhappy in marriage and, on the other, to those few who experitence extreme joy in marriage.

\begin{tabular}{lcc}
\hline Very & Happy & Perfectly \\
Unhappy & Happy
\end{tabular}

You will recognize the following questions from the questionnaire you completed before your baby was born. Would you kindly complete this section now, as it is a new period in your life as a married couple?

State the approximate extent of agreement or disagreement between you and your mate on the following items. Please check each column or space.

$$
\begin{aligned}
A A & =\text { Always Agree } & F D & =\text { Frequently Disagree } \\
A A A & =\text { Almost Always Agree } & A A D & =\text { Almost Always Disagree } \\
O D & =\text { Occasionally Disagree } & A D & =\text { Always Disagree }
\end{aligned}
$$

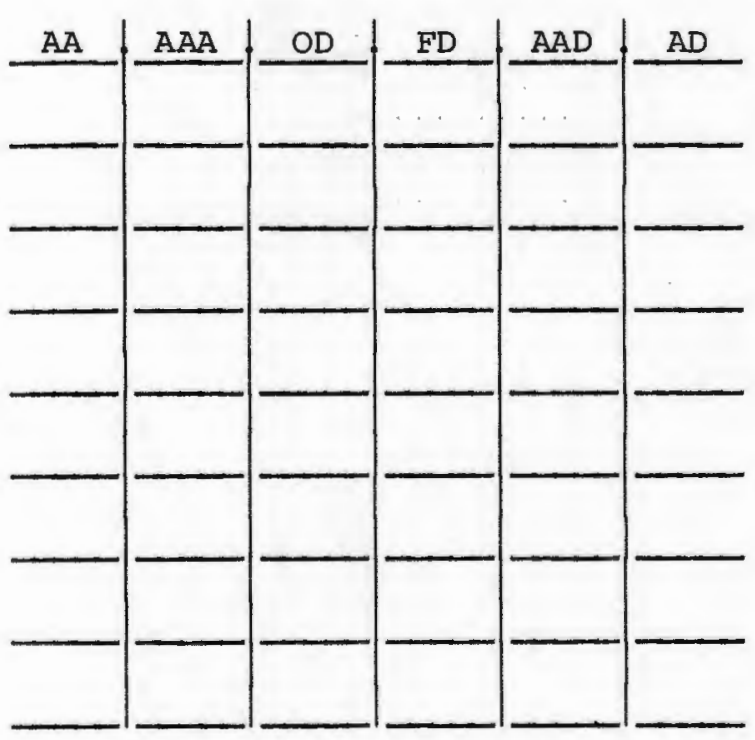

38. Handling family finances

39. Matters of recreation

40. Demonstrations of affection

41. Friends

42. Sex relations

43. Conventionality (right, good, or proper conduct)

44. Philosophy of life

45. Ways of dealing with in-laws

46. When disagreements arise, they usually result in husband giving in. wife giving in. agreement by mutual give and take. (Check only one)

47. Do you and your mate engage in outside interests together? All of them Some of them Very few of them None of them (Check only one)

48. In leisure time, do you generally prefer to be "on the go"? to stay at home? (Check only one) 
49. Do you ever wish you had not married?

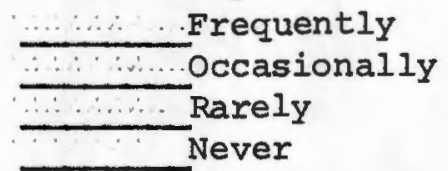

$$
\text { (Check only one) }
$$

50. If you had your life to live over, do you think you would marry the same person? marry a different person? not marry at all?

(Check only one)

51. Do you confide in your mate?

Almost never

Rarely

In most things

In everything (Check only one) 
Data Tables

Means, Standard Deviations, and Ranges of

All Variables for

Entire Sample and for Experimental and Control Groups 
Table VI

Husbands and Wives in Entire Sample: Means, Standard Deviations, and Ranges of Age, Education Completed, Length of Marriage Social Status Score, and Marital and Parenthood Adjustment scores $(\mathrm{N}=25)$

Variables

Age (years)

Husbands

Wives

\begin{tabular}{cl} 
Mean & $\begin{array}{l}\text { Standard } \\
\text { Deviation }\end{array}$ \\
\hline
\end{tabular}

4.015

4.245

$$
\begin{aligned}
& 25.96 \\
& 24.24
\end{aligned}
$$

Education Completed (years)

Husbands

Wives

Length of Marriage (years)

Social Status score

Marital Adjustment Scores

Prenatal

Husbands

Wives

Husbands and wives

Postpartum

$$
\begin{aligned}
& \text { Husbands } \\
& \text { Wives } \\
& \text { Husbands and Wives }
\end{aligned}
$$

Parenthood Adjustment score

$$
14.16
$$

14.16

2.80

45.68

109.76

111.80

110.78

112.56

115.64
114.10
17.982

19.378

17.023

21.325

21.229

18.905
Range

Min. Max.

$18.00 \quad 38.00$

$17.00 \quad 33.00$
2.593

10.00

$10.00 \quad 18.00$

0.50

8.25

$14.00 \quad 79.00$
Husbands

Wives

Husbands and Wives
50.12

56.56

53.34
9.071

11.931

9.730
$70.00 \quad 147.00$

$71.00 \quad 147.00$

$76.00 \quad 147.00$

$87.00 \quad 149.00$

$63.00 \quad 149.00$

$76.50 \quad 148.00$ 
Table VII

Husbands and Wives in Experimental Group: Means, Standard Deviations, and Ranges of Age, Education Completed, Length of Marriage, Social Status Score, and Marital and Parenthood Adjustment Scores

$$
(\mathrm{N}=14)
$$

Variables

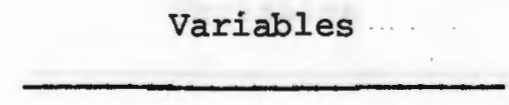

Age (years)

Husbands

Wives

Education Completed (years)

Husbands

wives

Length of Marriage (years)

Social status score

Marital Adjustment score

Prenatal

Husbands

Wives

Husbands and Wives

Postpartum

Husbands

Wives

Husbands and Wives

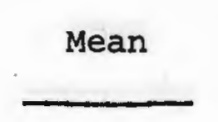

27.64

25.71

15.00

15.07

3.28

38.93

110.43

109.71

110.07

109.93

113.50

111.71

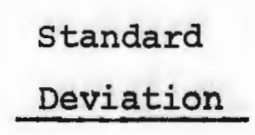

3.915

4.322

2.219

2.018

1.832

16.900
Range

Min. Max.

24.00

38.00

$20.00 \quad 33.00$ 
Table VIII

Husbands and wives in Control Group: Means, Standard Deviations, and Ranges of Age, Education Completed, Length of Marriage, Social Status Score, and Marital and Parenthood Adjustment Scores

$$
(\mathbb{N}=11)
$$

Variables

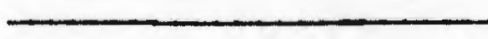

Age (years)

Husbands

Wives

Education Completed (years)

Husbands
Wives

Length of Marriage (years)

Social Status Score

Marital Adjustment Scores

Prenatal

Husbands

Wives

Husbands and Wives

Postpartum

Husbands

Wives

Husbands and Wives
13.09

13.00

2.18

54.27

108.91

114.45

111.68

115.91

118.36

117.14
Standard

Deviation
Range

Min. Max.
3.125

3.472

2.737

2.324

1.803

20.895

19.00

18.00

27.00

17.00

27.00 